This PDF is a selection from an out-of-print volume from the National Bureau of Economic Research

Volume Title: Tax Policy and the Economy, Volume 11

Volume Author/Editor: James M. Poterba, editor

Volume Publisher: MIT

Volume ISBN: 0-262-16167-2

Volume URL: http://www.nber.org/books/pote97-1

Conference Date: October 22, 1996

Publication Date: January 1997

Chapter Title: Health Insurance for Poor Women and Children in the U.S.: Lessons from the Past Decade

Chapter Author: Jonathan Gruber

Chapter URL: http://www.nber.org/chapters/c10908

Chapter pages in book: (p. $169-211)$ 


\section{HEALTH INSURANCE FOR POOR WOMEN AND CHILDREN IN THE U.S.: LESSONS FROM THE PAST DECADE}

\section{Jonathan Gruber MIT and NBER}

\section{EXECUTIVE SUMMARY}

The Medicaid program, which provides health insurance coverage to low income women and children, has expanded dramatically over the past decade. This expansion provides a "natural laboratory" for learning about the effect of public health insurance eligibility on insurance coverage, health care utilization, and health outcomes. This paper provides an overview of what has been learned about these questions from studying the expansions. Medicaid eligibility rose steeply over the 1984-1992 period, but coverage rose much less sharply, due to limited takeup of benefits. This is partly due to the fact that many eligibles already had private insurance coverage, and evidence suggests that a large share of new enrollees dropped their private coverage to join the program. Nevertheless, utilization of preventive care rose substantially as a result of the expansions, and there were significant improvements in health outcomes, specifically infant and child mortality. While these mortality reductions came at significant cost to the Medicaid program, the cost per life saved was low relative

This paper draws heavily on research that I have completed jointly with Janet Currie and David Cutler; I am indebted to both of them for their insights during the course of these joint projects. I am also grateful to Jim Poterba, whose comments motivated this undertaking, and to the National Institute of Aging for financial support. 
to alternative uses of government funds. These findings highlight both the potential benefits of public insurance policy and the importance of appropriately targeting scarce public health dollars.

\section{INTRODUCTION}

The United States is alone among major industrialized nations in not having a universal guarantee of insurance coverage for its citizens. As a result, over 40 million Americans are currently uninsured (Employee Benefits Research Institute, 1995). But this large uncovered population should not be taken to indicate that the U.S. government does not intervene in the market for health insurance to help those unable to obtain coverage. On the contrary, the single fastest growing federal entitlement program over the past decade is the Medicaid program, which provides health insurance coverage for low income populations. In 1984, federal Medicaid expenditures were $\$ 20.1$ billion, which was only $2.2 \%$ of the federal budget; by 1994 , expenditures are projected to have grown by almost $500 \%$, encompassing $5.6 \%$ of the federal budget. But, over this same period, the number of persons without insurance has grown by almost $20 \%{ }^{1}$

The fact that this rapid growth in the Medicaid program has not checked the growth in the uninsured highlights the limitations of current public insurance policy as a means of guaranteeing universal access to the health care system. However, with universal coverage effectively erased from the policy horizon, partial solutions to the access problem such as the Medicaid program are likely to be the alternative of choice for dealing with this problem in the near future. It is therefore important to understand how this program affects the access to medical care and health outcomes of the low income population in the U.S., and how precious Medicaid dollars should be spent most efficiently in delivering care to the underserved.

In fact, our understanding of the effects of the Medicaid program has improved substantially over the past five years. This improvement has been the direct result of a number of dramatic shifts in Medicaid policy towards pregnant women and children, both at the state and federal level, during the late 1980s and early 1990s. These substantial shocks to the policy environment have created a "natural laboratory" for trying to understand the costs and benefits of the Medicaid program for these populations, and a large number of papers since the early 1990s have

I Data on Medicaid spending from U.S. Congress Committee on Ways and Means (1994); data on budget from Economic Report of the President (1995); data on insurance coverage from Employee Benefit Research Institute (EBRI) (1995). 
exploited the availability of this changing policy environment to draw provocative conclusions about the impact of the Medicaid program. This impressive accumulation of data on the performance of the Medicaid program can provide the basis for thinking about health policy towards the indigent in the coming years.

The purpose of this paper is to critically survey the recent literature on Medicaid, with an eye towards the policy lessons that we have learned, and the questions that remain unanswered. I begin by providing a brief overview of the evolution of recent Medicaid policy in Part 2. At this stage, I also outline the process by which legislated changes in Medicaid eligibility can be traced through to the outcomes of ultimate interest, health improvements and program cost increases. In Part 3, I describe the increases in eligibility that resulted from the expansions, and discuss the extent to which this eligibility has been translated to increased insurance coverage, through the takeup of Medicaid by eligibles. In this context, I highlight the potential for the "crowdout" of private insurance coverage by Medicaid, and review evidence on the magnitude of this crowdout effect. In Part 4, I discuss the critical question of what impact Medicaid policy has had on the medical utilization and health status of the poor. In particular, I contrast the costs and benefits of different types of interventions that we have experienced over this period. In Part 5, I turn to the other areas in which Medicaid has had important effects. Part 6 summarizes what we have learned, and highlights the key issues for Medicaid policy reform.

\section{BACKGROUND-MEDICAID POLICY}

\subsection{Legislative Background}

At the outset, it is important to highlight that Medicaid is a program that serves three distinct populations: low income women and children; the low income disabled; and the low income elderly, and in particular nursing home residents. Spending is split roughly evenly between these three groups. In this paper, I will focus on the first of these groups, women and children. This focus is dictated by three considerations. First, the eligibility of low income women and children is the part of the program that has undergone the most radical change over this time period. Second, and related, this is the part of the program that has been the subject of the most study by economists. ${ }^{2}$ Finally, if Medicaid is cut

2 Indeed, the other aspects of the program have been virtually ignored by the research community; for a recent exception, see Yelowitz (1996). This is unfortunate given their fiscal importance. 
back, this is the population which may see the largest reductions in eligibility.

Historically, Medicaid eligibility for women and children has been tied to participation in the Aid for Families with Dependent Children program (AFDC). This linkage to AFDC greatly restricted access to the Medicaid program. Despite the existence of the AFDC-Unemployed Parents program (AFDC-UP), which provides benefits to households in which the primary earner is unemployed, AFDC benefits are generally available only to single-parent households. ${ }^{3}$ Moreover, income cutoffs for cash welfare vary across states, and can be very low. For example, in 1984, the cutoff for a family of 4 in South Carolina was only $29 \%$ of the poverty line.

There were a number of other programs offered at the discretion of the states, under which poor women and children could qualify for Medicaid, including the Medically Needy program (which allowed families to qualify for Medicaid if their incomes were somewhat above the cutoff but their medical expenses were particularly high); the Ribicoff Children program (which allowed states to cover children in two-parent families who met the AFDC income criteria); and other special options to cover women without children who met the AFDC income criteria for the expenses of their pregnancy only. While these options relaxed the family structure restrictions for the Medicaid program in some cases, eligibility was still restricted only to very poor persons.

Beginning in 1984, however, the Medicaid program began to expand eligibility for all children, and for pregnant women; that is, for women, these expansions applied only to the expenses of pregnancy. Changes in Medicaid policy since 1984 can be broadly categorized into two eras. The first, from 1984-mid-1987, was a period of incremental increases in Medicaid eligibility for populations that had similar financial circumstances to AFDC families, but who did not meet the eligibility criterion for other reasons. This began a gradual weakening of the linkage between AFDC coverage and eligibility for Medicaid. This occurred both at the state level, for example through expansions of the Ribicoff program option, 4 and at the federal level, through the 1984 DEFRA and 1985 COBRA legislations. Table 1 summarizes the federal legislation of this era.

${ }^{3}$ Many states did not have an AFDC-UP program until all were mandated to include them in 1991; among those that did, eligibility requirements were strict. As a result, as of 1990 only $5 \%$ of the AFDC caseload qualified under this program (U.S. Congress, Committee on Ways and Means, 1994).

${ }^{4}$ In 1984, only 23 states offered the Ribicoff Children program; by 1987, this had expanded to 32 states, although some states limited eligibility to somewhat younger children (less than age 17,18 , or 19, instead of the traditional cutoff of age 21). 


\section{TABLE 1}

The Medicaid Expansions

Deficit Reduction Act, 1984: Effective October 1, 1984. Required states to extend Medicaid coverage to children born after September 30, 1983, if those children lived in families that were income-eligible for AFDC. Mandatory coverage of pregnant women by AFDC if those women would be eligible once the child was born. Mandatory coverage of pregnant women under the AFDC-UP program, even if the state did not have such a program for all groups.

Consolidated Omnibus Reconciliation Act, 1985: Effective July, 1986. Pregnant women who meet AFDC resource standards are eligible for Medicaid regardless of family structure.

Omnibus Budget Reconciliation Act, 1986: Effective April 1, 1987. Permitted states to extend Medicaid coverage to pregnant women and children in families with incomes below the federal poverty level. Beginning in fiscal year 1988, states could increase the age cutoff by one year each year, until all children under age five were covered.

Omnibus Budget Reconciliation Act, 1987: Effective July 1, 1988. Permitted states to cover children under age 2, 3, 4, or 5 who were born after September 30, 1983. Effective October 1, 1988, states could expand coverage to children under age 8 born after September 30, 1983. Allowed states to extend Medicaid eligibility to pregnant women and to infants up to one year of age in families with incomes up to $185 \%$ of the federal poverty level. States were required to cover children through age 5 in fiscal year 1989 and through age 6 in fiscal year 1990, if the families met AFDC income standards.

Medicare Catastrophic Coverage Act, 1988: Effective July 1, 1989. Required states to cover pregnant women and infants up to age 1 in families with incomes less than $75 \%$ of the federal poverty level. Effective July 1, 1990, the income threshold was raised to $100 \%$ of poverty.

Family Support Act, 1988: Effective April 1, 1990. Required states to continue Medicaid coverage for 12 months among families who had received AFDC in three of the previous six months, but who had become ineligible because of earnings.

Omnibus Budget Reconciliation Act, 1989: Effective April 1, 1990. Required states to extend Medicaid eligibility to pregnant women and children up to age 6 with family incomes up to $133 \%$ of the federal poverty line.

Omnibus Budget Reconciliation Act, 1990: Effective July 1, 1991. Required states to cover all children under age 19 who were born after September 30 , 1983 and whose family incomes were below $100 \%$ of the federal poverty level. 
The second era, from mid-1987 to the present, saw a more dramatic decoupling of Medicaid and AFDC through substantial increases in the income cutoff for Medicaid eligibility. These expansions substantially increased (in most states) the income that a family could have and still qualify for Medicaid, while providing these higher eligibility levels to all family structures, not just to single parent families. By 1992, states were required to cover all pregnant women and children under the age of 6 up to $133 \%$ of poverty (independent of family composition), and were allowed to expand coverage up to $185 \%$ of poverty. ${ }^{5}$ In addition, children born after September 30,1983, were mandatorily covered up to $100 \%$ of poverty (once again, independent of family composition).

While most of the legislative action over this period was at the federal level, there was tremendous heterogeneity in the impacts of Medicaid policy changes across the states. States initially had different qualification limits through AFDC and other optional programs (such as Ribicoff Children), and they took up the new options at different rates, so that there was a great deal of variation across states in both the size and timing of the expansions. There was also variation within states in the eligibility of children of different ages for the Medicaid expansions, due to different age thresholds in the laws. This variation is illustrated in Table 2, from Yelowitz (1995a). This shows the age and percent of poverty cutoffs for expansions to the youngest group of children in each state at three different points in time. ${ }^{6}$ In January, 1988, only some states had expanded eligibility, and the income and age cutoffs varied. By December, 1989, all states had some expansion in place since federal law mandated coverage of infants up to $75 \%$ of the poverty line; but some states had expanded coverage up to age 7 or 8 , and coverage ranged as high as $185 \%$ of the poverty line. By December, 1991, state policies were more uniform as the most restrictive federal mandates had taken place, but some variation in poverty cutoffs remained.

\subsection{How Does Medicaid Affect Health?}

Ultimately, the question of interest for policy makers is how these policy changes impacted the health of the low income population, and at what cost. To understand the effects of Medicaid policy on health, however, it is important to trace through the channels by which changes at the

5 Several states expanded coverage above $185 \%$ of poverty, but they did not receive federal matching funds for those enrolled.

6 There were also differential expansions to older children as well, adding further richness to the variation in legislation across the states. The age restrictions were couched either in terms of date of birth, calendar date, or both, giving rise to the fractional ages of eligibility in some states at a given point in time. 
legislative level are translated to actual health improvements. In this section I provide a brief overview of these channels; in the remainder of the paper, I review what we know about each of them.

The process by which Medicaid determines health is depicted in Chart 1 . The first step in evaluating the effect of Medicaid policy changes on outcomes of interest, such as health, is to examine the effects on the eligibility of persons for the Medicaid program. While these expansions clearly increased eligibility, the extent to which they did so is hard to state ex ante, given the fact that the cutoffs for different age groups are moving through different parts of the income distribution. Thus, it is important to assess the ex post effect of these policy prescriptions on the share of the population actually made eligible for the Medicaid program.

The next step is the translation of Medicaid eligibility into Medicaid coverage. An important general feature of social insurance programs is that individuals do not always take up the benefits for which they are eligible. For example, Blank and Card (1991) estimate that takeup of unemployment insurance benefits only about $2 / 3$, and Blank and Ruggles (1996) find similar takeup rates for the AFDC and Food Stamps programs. Thus, only some of the previously uninsured will take up the benefits for which they are entitled.

The previously uninsured are not the only group which takes up benefits, however. In fact, the majority of those made eligible for the expansions actually had private insurance already. Some of those individuals will find it attractive to drop that private insurance and join the Medicaid program; the incentives for and magnitudes of this "crowdout" of private insurance are described below.

Moreover, once covered by Medicaid, individuals will not automatically increase their utilization of medical care. Many physicians do not treat publicly insured patients possibly because public insurance programs generally reimburse at rates far below private fee levels. A number of observers have alleged that there is a shortfall in the supply of physicians willing to serve Medicaid patients. The American Medical Association (1991) reports that $26 \%$ of physicians described themselves as "nonparticipants" in the Medicaid program, and only $34 \%$ reported that they participated "fully" and were accepting new Medicaid patients. This problem is exacerbated by the fact that many of the patients who would be made eligible for public insurance are concentrated in areas that are underserved by physicians (Fossett and Peterson, 1989; Fossett et al., 1992). ${ }^{7}$

${ }^{7}$ For example, Fossett et al. (1992) compared Chicago neighborhoods with $50 \%$ of the population on welfare to neighborhoods with $10 \%$ of the population on welfare and found that there were twice as many physicians practicing in the wealthier areas (on a per child basis). 


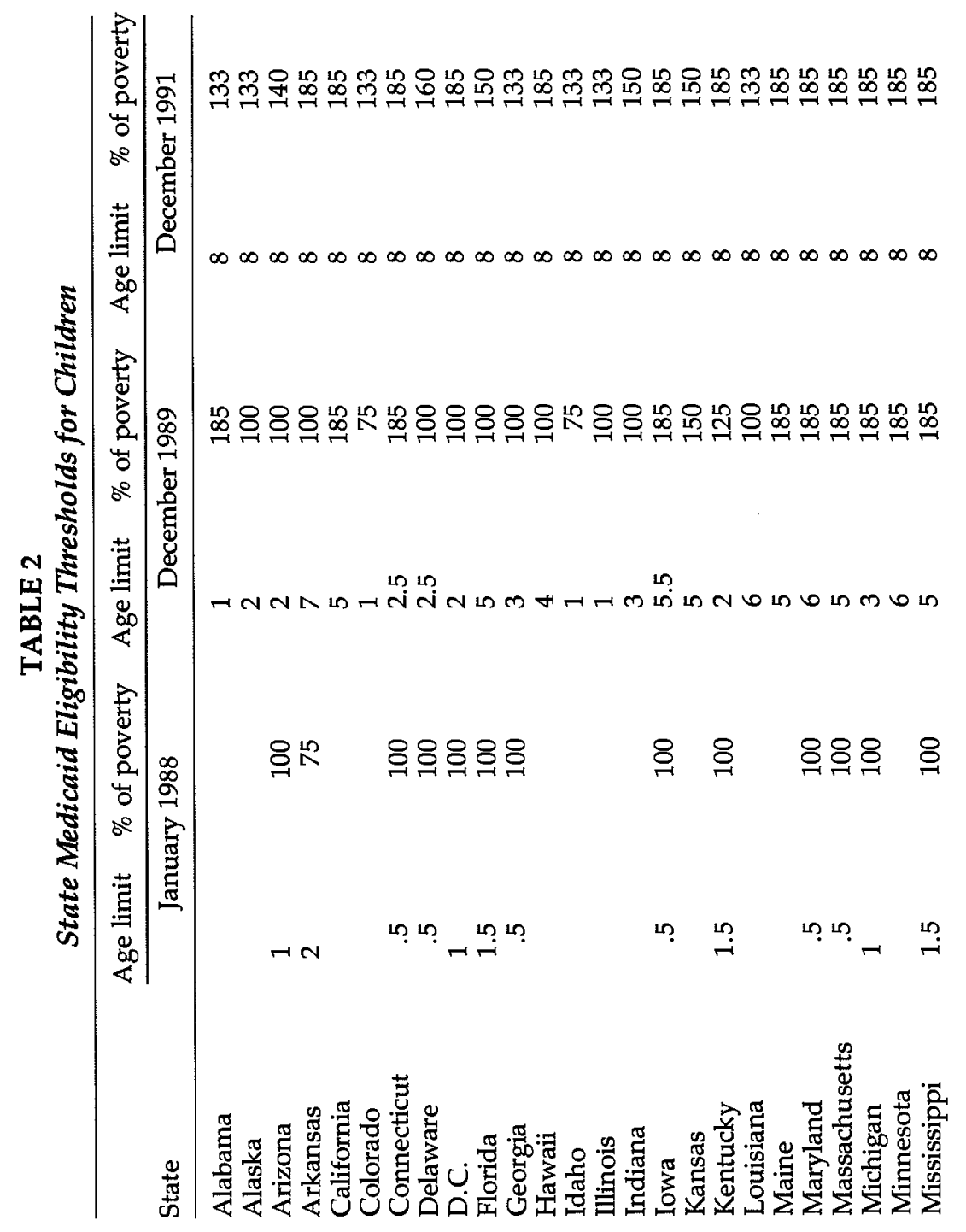




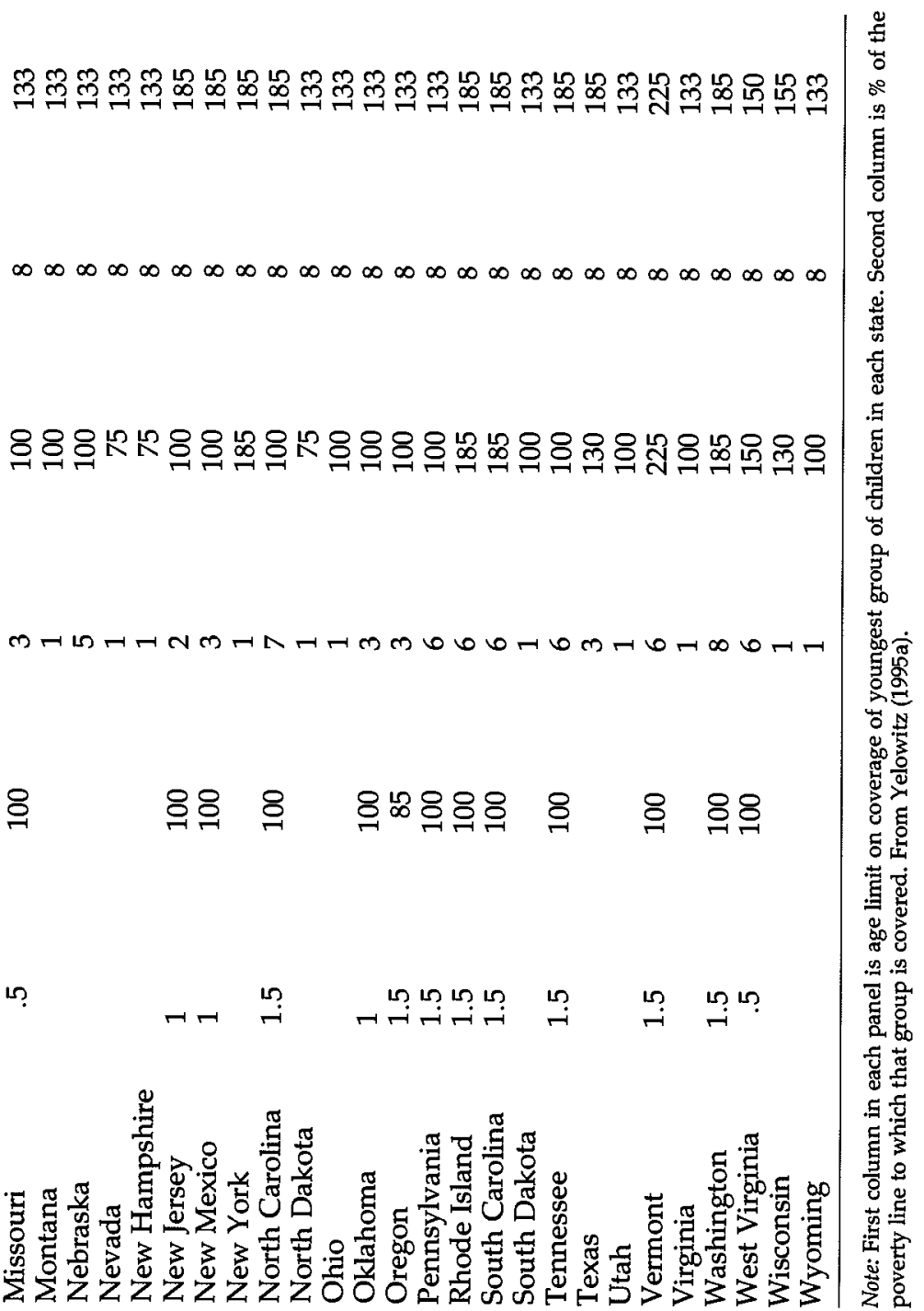


Medicaid Eligibility Policy

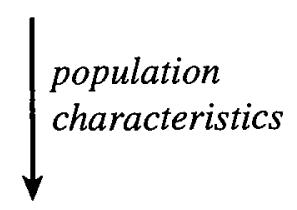

Increased Eligibility

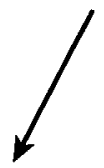

Previously

Uninsured

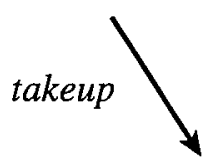

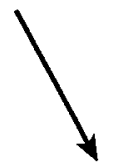

Previously Insured

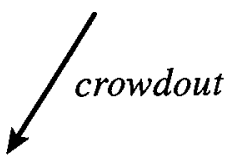

Medicaid Coverage

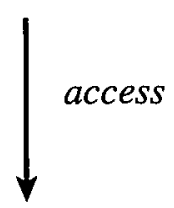

Health Utilization

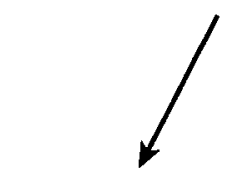

Program Costs
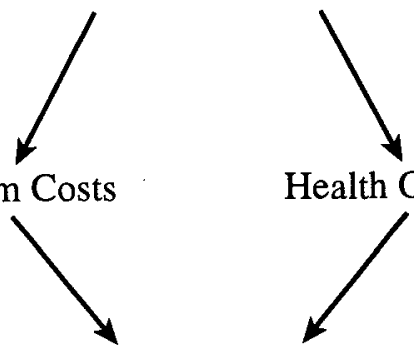

Health Outcomes

Cost Effectiveness

CHART 1 Medicaid Eligibility Policy 
Finally, increases in the utilization of care will not necessarily improve child health-for example, a number of studies suggest that much of the acute care received by children is inappropriate and may have little health benefit. ${ }^{8}$ Lurie et al. (1984) and Bindman et al. (1990) document positive effects of insurance on adult health, but a randomized trial (Newhouse, 1993) suggested that increasing the generosity of insurance coverage had little health benefit. Moreover, much of the discussion of Medicaid policy has focused on the insurance coverage of children. But neither of the first two studies looked at children, and there were too few children involved in the randomized trial for any firm conclusion regarding child health to be drawn (Valdez, 1985). Many economists (e.g., Fuchs, 1974) emphasize that medical care may actually be of limited relevance for health, relative to the other behavioral and environmental factors impacting on the health of low income persons.

Whether or not increases in utilization improve health outcomes, there is a definite link between increased utilization and increases in Medicaid program costs. Thus, the final step in assessing the efficacy of Medicaid policy is to compare the costs of utilization increases to any health benefits, to compute the cost effectiveness of eligibility increases. Below, I present direct evidence on cost effectiveness, as measured by the cost per life saved under the Medicaid program.

\section{ELIGIBILITY AND COVERAGE}

\subsection{Effects on Eligibility}

As noted above, the first step in tracing out the effect of the expansions is to measure the impact on eligibility. I measure eligibility for Medicaid using data from the March Current Population Surveys (CPS) for 1985 through 1993. Since the CPS asks about insurance and income with a one year lag, the data are for 1984 through 1992. To use these data, I have developed detailed simulation programs which model the Medicaid eligibility of women of child-bearing age and of children in each state and year. ${ }^{9}$ These programs input data on a family's income and family structure, run these data through a module which describes Medicaid policy as a function of these variables in each state and year, and output Medicaid eligibility for each member of that family. Since the CPS does

${ }^{8}$ Kemper (1988), for example, finds that $21 \%$ of pediatric hospitalization days were of "doubtful necessity," and that this fraction is higher for insured than for uninsured children.

9 These programs were developed in collaboration with Janet Currie, and are described in more detail in Currie and Gruber $(1996 a, b)$. Aaron Yelowitz also provided extensive assistance in this endeavor. 


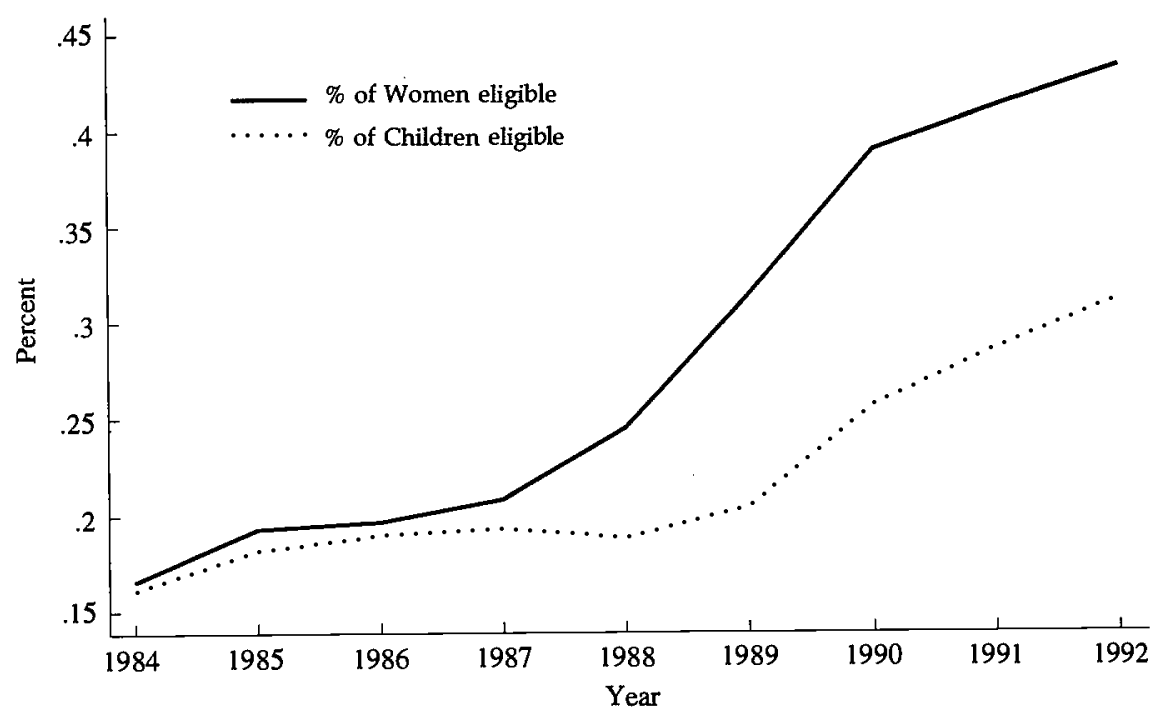

FIGURE 1: Medicaid Eligibility of Women and Children

not indicate whether a woman is pregnant, eligibility is imputed for all women of child-bearing age (15-44).

The results of applying the Medicaid rules to the CPS data are presented in Figure 1, for women age 15-44 and for children under age 15; it is important to keep in mind that Figure 1 refers to eligibility for the expenses of pregnancy only. For both groups, there is a gradual increase in eligibility from 1984 through 1987, and a much more rapid increase thereafter; these correspond to the two eras denoted above. By 1992, almost one-half of all women were eligible for Medicaid for the expenses of pregnancy, and almost one-third of children age 0-14 were eligible for all of their medical spending.

These national trends mask considerable heterogeneity across the states. In Table 3, I show the changes in eligibility for each state over this period, for children and for women. In the first column of each panel, I present the level of eligibility for 1984, in the second the level of eligibility in 1992, and in the third the difference between the two. While there are clearly large increases in eligibility on average, the differences across the states are striking. For pregnant women, the increase in eligibility ranged from a low of $4 \%$ in Utah to a high of $43 \%$ in Texas. For children, there was actually a decline in eligibility of $4 \%$ in Wisconsin, and a rise of $28 \%$ in Texas. Moreover, there is also considerable heterogeneity within 
TABLE 3

Eligibility by State

\begin{tabular}{|c|c|c|c|c|c|c|c|}
\hline \multicolumn{4}{|c|}{ Children } & \multicolumn{4}{|c|}{ Women 15-44 } \\
\hline State & 1984 & 1992 & Diff & State & 1984 & 1992 & Diff \\
\hline $\mathrm{AL}$ & 0.111 & 0.252 & 0.141 & $\mathrm{AL}$ & 0.150 & 0.528 & 0.378 \\
\hline AK & 0.179 & 0.208 & 0.029 & AK & 0.193 & 0.306 & 0.114 \\
\hline AR & 0.163 & 0.292 & 0.129 & AR & 0.129 & 0.453 & 0.324 \\
\hline CA & 0.294 & 0.406 & 0.112 & CA & 0.262 & 0.510 & 0.248 \\
\hline $\mathrm{CO}$ & 0.073 & 0.211 & 0.138 & $\mathrm{CO}$ & 0.116 & 0.379 & 0.264 \\
\hline $\mathrm{CT}$ & 0.122 & 0.273 & 0.151 & CT & 0.140 & 0.341 & 0.171 \\
\hline $\mathrm{DE}$ & 0.133 & 0.198 & 0.065 & $\mathrm{DE}$ & 0.057 & 0.373 & 0.316 \\
\hline DC & 0.427 & 0.474 & 0.047 & $\mathrm{DC}$ & 0.333 & 0.494 & 0.162 \\
\hline $\mathrm{FL}$ & 0.116 & 0.337 & 0.221 & FL & 0.127 & 0.492 & 0.364 \\
\hline GA & 0.120 & 0.327 & 0.207 & GA & 0.121 & 0.393 & 0.272 \\
\hline HI & 0.126 & 0.278 & 0.152 & $\mathrm{HI}$ & 0.205 & 0.372 & 0.167 \\
\hline ID & 0.065 & 0.292 & 0.227 & ID & 0.115 & 0.456 & 0.341 \\
\hline IL & 0.204 & 0.287 & 0.083 & IL & 0.193 & 0.358 & 0.164 \\
\hline IN & 0.089 & 0.272 & 0.183 & IN & 0.050 & 0.423 & 0.373 \\
\hline IA & 0.206 & 0.266 & 0.060 & IA & 0.233 & 0.494 & 0.261 \\
\hline $\mathrm{KS}$ & 0.065 & 0.190 & 0.125 & KS & 0.124 & 0.319 & 0.195 \\
\hline $\mathrm{K} Y$ & 0.117 & 0.330 & 0.213 & $K Y$ & 0.108 & 0.518 & 0.409 \\
\hline LA & 0.106 & 0.357 & 0.251 & LA & 0.142 & 0.505 & 0.363 \\
\hline $\mathrm{ME}$ & 0.165 & 0.335 & 0.170 & $\mathrm{ME}$ & 0.153 & 0.518 & 0.365 \\
\hline MD & 0.114 & 0.317 & 0.203 & MD & 0.115 & 0.370 & 0.256 \\
\hline MA & 0.152 & 0.259 & 0.107 & MA & 0.169 & 0.381 & 0.213 \\
\hline MI & 0.261 & 0.283 & 0.022 & MI & 0.222 & 0.441 & 0.219 \\
\hline $\mathrm{MN}$ & 0.143 & 0.325 & 0.182 & $\mathrm{MN}$ & 0.108 & 0.440 & 0.333 \\
\hline MS & 0.154 & 0.380 & 0.226 & MS & 0.167 & 0.595 & 0.429 \\
\hline $\mathrm{MO}$ & 0.116 & 0.329 & 0.213 & $\mathrm{MO}$ & 0.106 & 0.389 & 0.282 \\
\hline MT & 0.055 & 0.233 & 0.178 & MT & 0.127 & 0.380 & 0.253 \\
\hline NE & 0.170 & 0.221 & 0.051 & $\mathrm{NE}$ & 0.161 & 0.303 & 0.142 \\
\hline NV & 0.056 & 0.261 & 0.205 & NV & 0.051 & 0.381 & 0.330 \\
\hline $\mathrm{NH}$ & 0.061 & 0.167 & 0.106 & $\mathrm{NH}$ & 0.030 & 0.295 & 0.265 \\
\hline NJ & 0.164 & 0.223 & 0.059 & NJ & 0.177 & 0.422 & 0.245 \\
\hline NM & 0.088 & 0.318 & 0.230 & NM & 0.120 & 0.540 & 0.419 \\
\hline NY & 0.286 & 0.491 & 0.205 & NY & 0.281 & 0.489 & 0.208 \\
\hline $\mathrm{NC}$ & 0.068 & 0.299 & 0.231 & NC & 0.122 & 0.491 & 0.368 \\
\hline ND & 0.168 & 0.223 & 0.055 & ND & 0.138 & 0.369 & 0.231 \\
\hline $\mathrm{OH}$ & 0.173 & 0.267 & 0.094 & $\mathrm{OH}$ & 0.163 & 0.336 & 0.173 \\
\hline OK & 0.153 & 0.334 & 0.181 & OK & 0.128 & 0.449 & 0.321 \\
\hline OR & 0.060 & 0.243 & 0.183 & OR & 0.040 & 0.313 & 0.272 \\
\hline PA & 0.223 & 0.218 & -0.005 & PA & 0.219 & 0.336 & 0.117 \\
\hline RI & 0.194 & 0.292 & 0.098 & RI & 0.179 & 0.475 & 0.296 \\
\hline SC & 0.079 & 0.335 & 0.256 & $\mathrm{SC}$ & 0.117 & 0.544 & 0.427 \\
\hline SD & 0.050 & 0.227 & 0.177 & SD & 0.107 & 0.337 & 0.231 \\
\hline $\mathrm{TN}$ & 0.095 & 0.321 & 0.226 & TN & 0.110 & 0.500 & 0.390 \\
\hline
\end{tabular}


TABLE 3

Continued

\begin{tabular}{|c|c|c|c|c|c|c|c|}
\hline \multicolumn{4}{|c|}{ Children } & \multicolumn{4}{|c|}{ Women 15-44 } \\
\hline State & 1984 & 1992 & Diff & State & 1984 & 1992 & Diff \\
\hline TX & 0.069 & 0.348 & 0.279 & TX & 0.053 & 0.485 & 0.432 \\
\hline UT & 0.146 & 0.236 & 0.090 & UT & 0.260 & 0.302 & 0.043 \\
\hline VT & 0.192 & 0.356 & 0.164 & $\mathrm{VT}$ & 0.242 & 0.485 & 0.243 \\
\hline VA & 0.090 & 0.218 & 0.128 & VA & 0.053 & 0.298 & 0.245 \\
\hline WA & 0.126 & 0.246 & 0.120 & WA & 0.141 & 0.294 & 0.154 \\
\hline WV & 0.104 & 0.353 & 0.249 & WV & 0.157 & 0.527 & 0.370 \\
\hline WI & 0.266 & 0.218 & -0.048 & WI & 0.267 & 0.337 & 0.070 \\
\hline$W Y$ & 0.055 & 0.224 & 0.169 & $W Y$ & 0.103 & 0.335 & 0.232 \\
\hline
\end{tabular}

Note: Figures are fraction of children and women eligible for Medicaid in each state year, based on author's calculations.

states in the rate at which children of different ages were covered. For example, coverage of children under age 3 rose by over $30 \%$ in Texas, while coverage of children over age 10 rose by less than $5 \%$.

\subsection{Effects on Coverage}

The findings of Part 2 suggest a dramatic increase in the eligibility of both (pregnant) women and children for the Medicaid program. But, as highlighted earlier, this does not automatically translate into increased coverage by the Medicaid program. In fact, takeup problems are likely to be even larger for the Medicaid expansions, relative to other social insurance programs, due to the nature of the population that is being newly covered. This point is highlighted in Table 4 . This table presents data for the 1984 population of children and women age 15-44. I divide this population into three groups: those eligible for Medicaid in 1984; those who were not eligible in 1984, but who would be eligible by 1992 rules; and those who would not be eligible by 1992 rules. When I project future eligibility, I inflate 1984 incomes to 1992 levels using the CPI.

Table 4 shows two reasons why we might expect relatively low takeup of the Medicaid expansions. First, the population covered by the expansions was much less disadvantaged than was the population already eligible for Medicaid at the start of the period. Most importantly, they were relatively unlikely to be receiving public assistance through AFDC. Limited contacts with the social welfare system may make these persons unaware of the benefits for which they were newly entitled. Second, much of the population that was covered by the expansions already had insurance coverage from other sources before being made 
TABLE 4

Characteristics of Medicaid Eligibles

\begin{tabular}{lccc}
\hline & \multicolumn{3}{c}{ Eligibility status } \\
\cline { 2 - 4 } & $\begin{array}{c}\text { Made eligible } \\
\text { between } \\
\text { Characteristic }\end{array}$ & $\begin{array}{c}\text { Not eligible } \\
\text { in 1992 }\end{array}$ \\
\hline Share of population & & & \\
$\quad$ Demographics & 1984 & $28 \%$ & $56 \%$ \\
Female headed & $63 \%$ & $30 \%$ & $13 \%$ \\
Head is high school dropout & $45 \%$ & $25 \%$ & $12 \%$ \\
Head works & $51 \%$ & $88 \%$ & $95 \%$ \\
Family in poverty & $79 \%$ & $19 \%$ & $2 \%$ \\
Mean family income & $\$ 10276$ & $\$ 18517$ & $\$ 38263$ \\
Family receives AFDC & $47 \%$ & $5 \%$ & $1 \%$ \\
Insurance coverage & & & \\
Private & $23 \%$ & $69 \%$ & $88 \%$ \\
Public & $52 \%$ & $7 \%$ & $2 \%$ \\
Uninsured & $29 \%$ & $26 \%$ & $11 \%$ \\
\hline
\end{tabular}

eligible for Medicaid. Indeed, two-thirds of those made eligible for Medicaid already had private insurance coverage. Thus, the demand for taking up Medicaid may be much lower, even conditional on being aware of one's eligibility.

In fact, previous research documents quite low takeup rates for Medicaid. Cutler and Gruber (1996a), for example, find a takeup rate of only $23 \%$ for children; Currie and Gruber $(1996 a, b)$ estimate takeup rates of $23 \%$ for children and $34 \%$ for women of child-bearing age. This finding suggests that there is only weak translation of the tremendous eligibility expansions into Medicaid coverage, a fact that is confirmed by Figure 2, which shows time series data on coverage for children and women of child-bearing age. While both series rise steeply, the increase is much less than that of eligibility; moreover, much of the rise after 1989 is due to the recession, not due to eligibility policy.

\subsection{Medicaid and Crowdout}

The fact that such a large share of the newly eligible population under the Medicaid expansions had access to private insurance raises the prospect that many of the new enrollees on the program may have been "crowded out" of private insurance purchases. The crowdout of private insurance mechanisms by public interventions has been the subject of a 


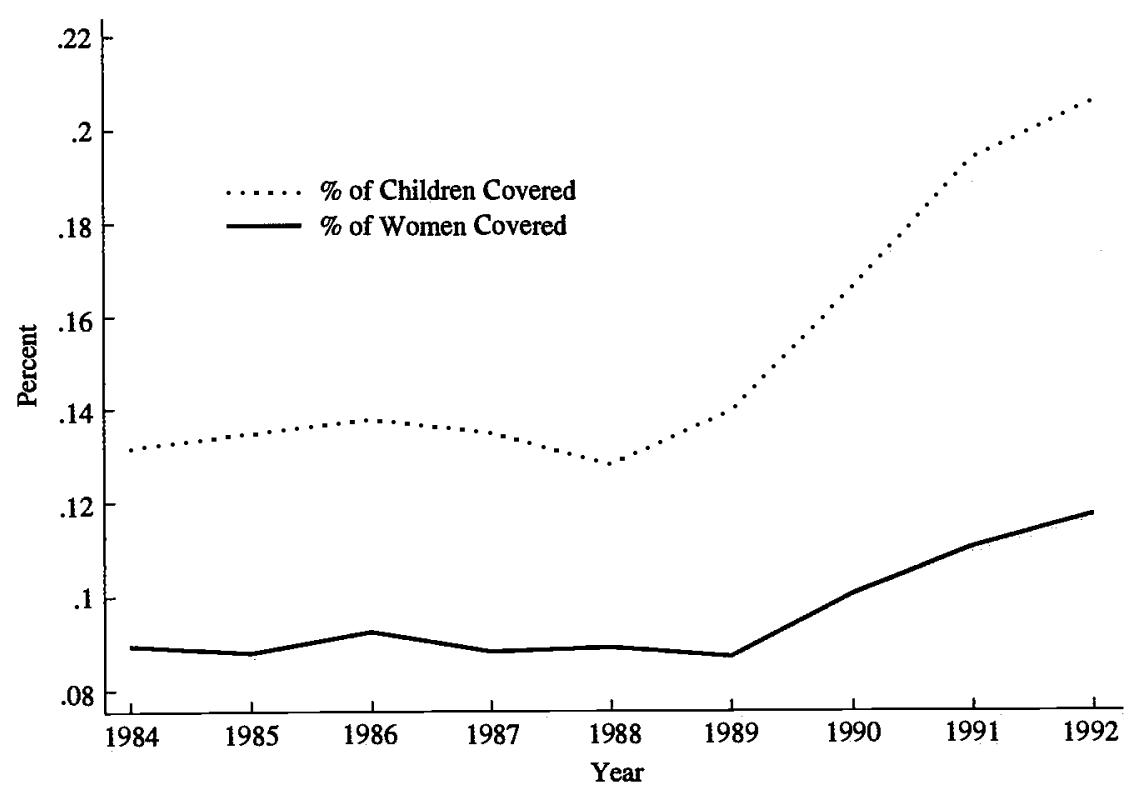

FIGURE 2: Medicaid Coverage of Women and Children

long literature, but the first paper to specifically consider the interaction of private and public health insurance was Cutler and Gruber (1996a). That paper begins by discussing the extent to which we might anticipate crowdout. Crowdout will occur to the extent that some individuals who are made eligible already have private insurance (as was demonstrated to be the case in Table 4), and to the extent that those individuals find Medicaid a more attractive option. Along some dimensions, Medicaid is a much more generous plan than most private policies, since it has no copayments, covers prescription drugs, and often covers optional services such as dental care. In contrast, under the typical private insurance policy individuals pay one-third of their total medical costs out of pocket, in the form of copayments, deductibles, and premium-sharing.

For many reasons, however, the value of Medicaid is below that of private policies. Because of low Medicaid reimbursement rates, providers are often reluctant to treat Medicaid patients (Currie, Gruber, and Fischer, 1995), thus reducing the value of coverage. In addition, individuals may not want to be enrolled in public programs, because of the stigma associated with public programs or the difficulty in enrolling. Finally, the value of Medicaid may be low because individuals may have 


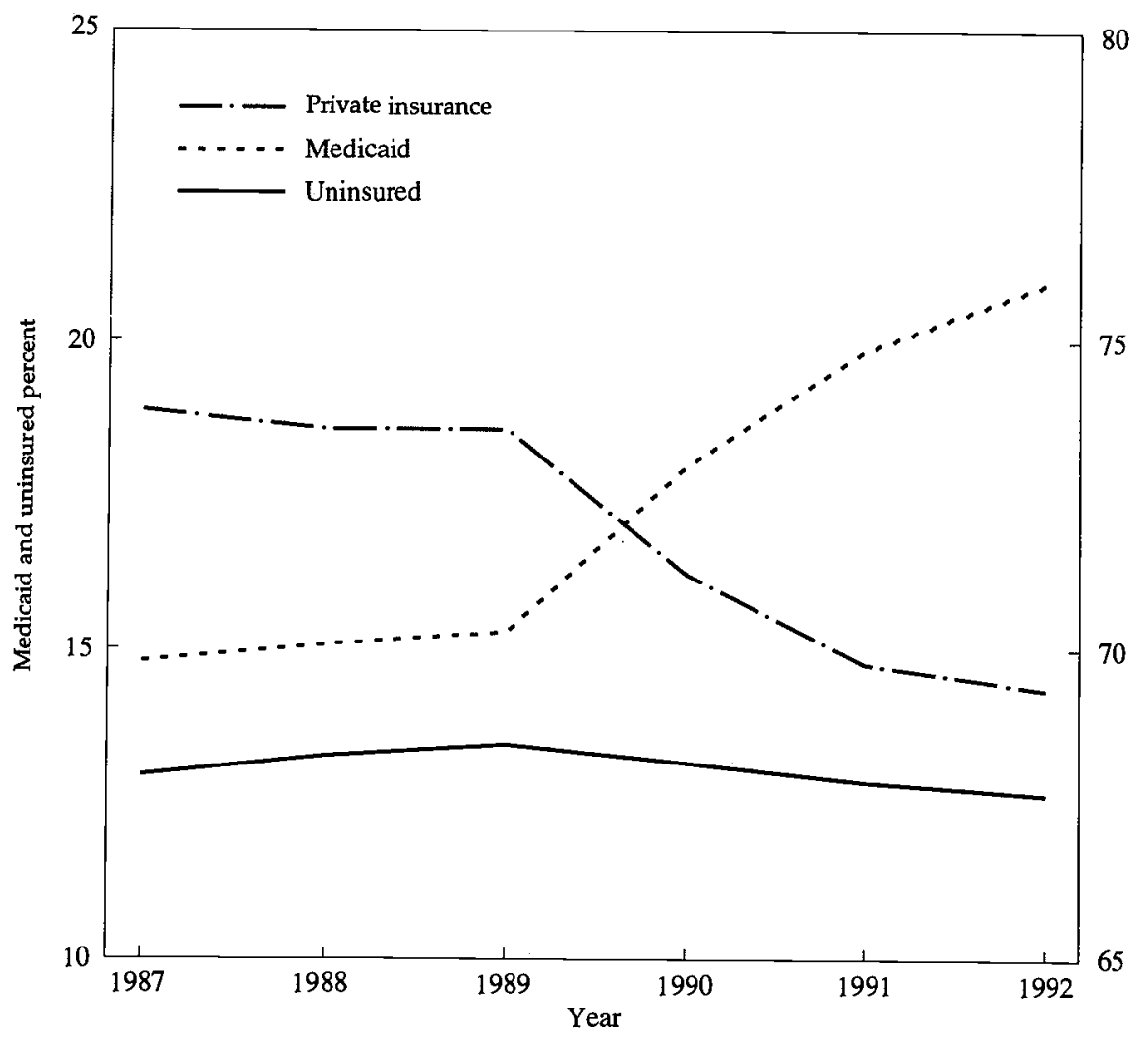

Note: Based on March CPS Surveys for 1988 through 1993.

\section{FIGURE 3: Health Insurance Coverage of Children}

difficulty shifting from Medicaid back into private coverage if they have preexisting medical conditions. Thus, the extent to which the newly Medicaid-eligible population would drop their private coverage to obtain medicaid coverage is an empirical question.

The time series evidence on insurance coverage in the U.S. would seem to confirm the crowdout hypothesis; there is a remarkable time series correlation between Medicaid coverage and private insurance coverage over this period. Figure 3 documents this correlation for children. The time series movements in Medicaid and private insurance mirror each other; as a result, there was little change in the number of children uninsured. However, it is difficult to draw strong conclusions from this evidence because the recession during this time period would cause 
both private insurance to fall and Medicaid enrollment to grow, even in the absence of crowdout.

The approach used by Cutler and Gruber is therefore to exploit the tremendous variation in Medicaid eligibility across states, within states over time, and even within states at a point in time (from age notches in eligibility). They use the CPS data and eligibility imputations described above to estimate models of the effect of Medicaid eligibility on private insurance coverage over the 1987-1992 period. A key feature of this paper is the recognition that there may be within-family spillovers in insurance coverage decisions. That is, it may be inappropriate to model a child's private insurance coverage as a function of that child's eligibility only. This is because private health insurance is generally sold only for individuals or families, without gradations among types of dependents. Thus, a family that wants to cover both parents but not the children (because the children may qualify for Medicaid) may find it impossible to do so with only one policy. Similarly, there is often no savings from enrolling some dependents on a policy but not others. This lack of distinction among dependents may increase or decrease the amount of crowdout. To the extent that families value coverage of all members and some members cannot qualify for public coverage, crowdout is likely to be smaller than an individual-by-individual calculation would suggest. On the other hand, if the Medicaid subsidy is large, families may drop coverage of all members, even those who do not qualify for public insurance directly. In either case, accounting for within-family spillovers is key. ${ }^{10}$

Cutler and Gruber account for the effect of Medicaid eligibility on the family's insurance coverage decisions by modeling each family member's insurance coverage as a function of the "Medicaid replacement rate": the share of expected family medical spending that is made eligible for Medicaid. The results of this exercise are summarized in Table 5, from Cutler and Gruber (1996a). They estimate that the Medicaid expansions brought 1.5 million children and 700,000 women onto the Medicaid rolls. At the same time, they were responsible for 600,000 children, 800,000 women, and 300,000 other family members dropping their private insurance coverage in order to take advantage of free Medicaid

10 A similar argument might suggest that there might also be within-firm spillovers, through the decisions of employers to stop offering insurance when much of their workplace was Medicaid eligible. Cutler and Gruber find no evidence of an effect of Medicaid eligibility on employer decisions to offer insurance, however; all of the crowdout effect appears to come through employee takeup decisions. At the same time, they find some suggestive evidence that employers are increasing premium-sharing in response to the expansions, in order to induce lower takeup of workplace coverage and a shift to the public program. 
TABLE 5

Effect of Medicaid Expansions on Insurance Coverage

\begin{tabular}{lcc}
\hline & \multicolumn{2}{c}{ Change in coverage (millions) } \\
\cline { 2 - 3 } Coverage of: & Medicaid & Private \\
\hline Children & 1.5 & -0.6 \\
Women 15-44 & 0.7 & -0.8 \\
Other adults & 2.2 & -0.3 \\
Total & & -1.7 \\
Conditional coverage of women & 0.9 & $(-77 \%)$ \\
Conditional coverage of children & 0.4 & - \\
Total & 3.5 & -1.7 \\
& & $(-49 \%)$ \\
\hline
\end{tabular}

Note: Shows change in Medicaid and private coverage of women and children due to the expansions.

Each cell is number of persons (in millions). From Cutler and Gruber (1996a).

coverage. The greater than $100 \%$ crowdout for women, and the effect on other family members, is a by-product of within-family spillovers.

But the estimated increase in the Medicaid rolls is an underestimate of the true increase in the availability of Medicaid to these populations. The Medicaid expansions explicitly did not give continuous coverage to women. Rather, they created a form of conditional coverage-women are covered, but only for some expenses. As a result, women who are eligible for Medicaid in the event of pregnancy but who report themselves to be uninsured actually have some partial (conditional) insurance coverage. In particular, these women will have their hospital bills for delivery covered, since hospitals have developed detailed systems to insure that uninsured persons who are eligible for Medicaid get signed up for the program.

In the same vein, Medicaid also provides a form of conditional coverage for uninsured children. The fact that these children are not continuously covered by Medicaid suggests that they are not availing themselves of the insurance for the purpose of their primary medical care. Once again, however, when these children need hospital services, they may be signed up for Medicaid, so that they have conditional coverage for their hospital spending.

Cutler and Gruber value conditional coverage for women as the share of average annual medical spending that is accounted for by hospital expenses for pregnancy (25\%), and for children as the share of annual total spending that is at the hospital (44\%). Doing so, shown in the next set of rows in Table 5, increases the estimated coverage increase to 3.5 
million people: Accounting for conditional coverage, the bottom line estimate is that $50 \%$ of the increase in Medicaid eligibility was associated with a reduction in private insurance coverage.

This is a sizeable effect, suggesting the importance of this issue for Medicaid policy design. Nevertheless, these results also suggest that at least half of those enrolling in Medicaid were previously uninsured, so that there was a large net improvement in health insurance coverage in the U.S. as a result of the expansions. ${ }^{11}$

\section{EFFECTS ON UTILIZATION OF HEALTH CARE AND HEALTH OUTCOMES}

A natural motivation for increasing the eligibility of the low income population for public insurance is to improve their health. But, as highlighted above, there are a number of reasons why increased health insurance does not guarantee improved health outcomes. Thus, simply documenting that the Medicaid expansions increased insurance coverage is not enough to prove that they improved health. In this section, I therefore review studies which focus directly on the effects of the expansions on health care utilization and health outcomes. These studies focus in particular on use of preventative care and on directly measurable outcomes such as mortality and fetal health (i.e., low birthweight). ${ }^{12}$

\subsection{Observational Analyses}

A number of studies have assessed the effects of Medicaid by comparing the utilization and health of persons with Medicaid coverage, relative to the uninsured. These studies have shown that uninsured persons have lower utilization levels, a less efficient distribution of utilization across sites of care, and worse health outcomes (e.g., Kasper, 1986; Short and

11 Cutler and Gruber (1996b) estimate that in fact as much as $80 \%$ of the newly enrolled Medicaid population was previously uninsured. The difference between the $50 \%$ and $80 \%$ figures is the population that dropped private insurance due to the expansions, but didn't enroll in Medicaid (e.g., women who are waiting for pregnancy to enroll). Since Cutler and Gruber (1996a), several further studies have estimated the crowdout of private insurance by Medicaid. Rask and Rask (1995) and Currie (1996) also found substantial crowdout. Dubay and Kenney (1996) find smaller crowdout overall, but similar effects for those above the poverty line; for a comparison of those results to Cutler and Gruber (1996a), see Cutler and Gruber (1996c).

12 This focus is dictated by the empirical difficulties with using measures of acute care (since, if Medicaid affects health, it will have a feedback effect on use of acute care) and self-reported health (since increased contacts with the medical system may worsen perceptions of health through improved medical information). See Currie and Gruber (1996b) for a more detailed discussion of these issues. 
Lefkowitz, 1992; Mullahy, 1994). But since the uninsured are likely to differ from the insured in both observable and unobservable respects, it is difficult to draw causal inferences from these types of comparisons. Furthermore, insurance coverage itself may be a function of health status, leading to endogeneity bias in estimates of the effects of insurance on health and on the utilization of medical care.

\subsection{Pre-Post Analyses}

A natural alternative approach to analyzing the effect of Medicaid on utilization and health is to contrast the experience of a single state before and after it expands its Medicaid program. This approach has been the focus of two important studies of prenatal care use and infant outcomes, Piper et al. (1990) and Haas et al. (1993a). ${ }^{13}$ Piper analyzed the effect of the extension of Medicaid coverage to low income married women in Tennessee in 1985; Haas et al. examined the effect of expanding Medicaid coverage to women with incomes under $185 \%$ of the poverty line in Massachusetts in 1985.14

Both of these studies have a common finding: there was no effect of insurance expansions on either use of prenatal care or infant outcomes. Piper et al. suggest one reason for this finding: more than two-thirds of the women who were eligible for Medicaid enrolled after the first trimester of pregnancy; almost $30 \%$ enrolled in the last 30 days before birth. ${ }^{15}$ The extent of late enrollment grew after the expansion of Medicaid, suggesting that the newly eligible were enrolling even later. Ellwood and Kenney (1995) use more recent data to refute this contention, however, finding that, among women who were newly enrolled for their pregnancy, the expansion population was as successful as the AFDC population in enrolling the first trimester. Even in the Ellwood and Kenney data, however, only about one-half of the newly enrolling women were enrolled during the first trimester. A large literature on the effectiveness of prenatal care suggests that it is receipt of care in the first trimester that is key for improving fetal health (Institute of Medicine, 1985). Thus, it is perhaps unsurprising that there was no effect on outcomes of these expansions.

13 I am aware of no such studies focusing on children.

14 The Massachusetts expansion was not technically a Medicaid policy, but rather a stateonly program for the uninsured; but it foreshadowed the expansions that would be implemented under the Medicaid programs several years later.

15 Howell and Ellwood (1991) study this question for an earlier period (1983), and they find that roughly $50-60 \%$ of women whose deliveries were paid for by Medicaid were enrolled in Medicaid in the first trimester. 
While informative, these studies suffer from two potentially important problems. First, they are unable to control for correlated time series trends in the use of prenatal care and birth outcomes. There are a number of other changes in the circumstances of low income households in the 1980s which might lead to lower use of prenatal care or worse outcomes, such as the erosion of the real earnings of low wage earners (Katz and Murphy, 1992). These could interfere with uncovering the true effect of the Medicaid expansions. Second, the experience of one state's program may not be broadly prescriptive for the effects of national Medicaid policy.

\subsection{Combining the States-Methodology}

An alternative approach involves using the experience of not just one or two states, but all of the states, to assess the effects of changing Medicaid policy. By comparing more broadly states that do and do not increase Medicaid generosity over time, one can also control for correlated time series trends. This is the approach taken by Currie and Gruber (1996a) for the case of prenatal care utilization and infant outcomes, and Currie and Gruber (1996b) for the case of child health care utilization and health outcomes. In both cases, the authors use individual-level data on health care utilization, either from the National Longitudinal Survey of Youth (NLSY) on pre-natal care utilization, or from the National Health Interview Survey (NHIS) on child health care utilization. They combine this with aggregate data on mortality outcomes from the Vital Statistics. In all cases, the data are a time series of national cross-sections, providing information on a number of states over time.

These data are used to run regressions of the form:

$$
\begin{aligned}
\operatorname{OUTCOME}_{\mathrm{ijt}}=\alpha & +\beta_{1} \mathrm{X}_{\mathrm{ijt}}+\beta_{2} \mathrm{ELIG}_{\mathrm{ijt}}+\beta_{3} \delta_{\mathrm{j}} \\
& +\beta_{4} \tau_{\mathrm{t}}+\epsilon_{\mathrm{ijt}}
\end{aligned}
$$

where OUTCOME $\mathrm{ijt}_{\mathrm{ijt}}$ is a measure of utilization or health outcome for person $i$ (or group $i$ ) in state $j$ in year $t, X$ is a set of control variables, ELIG is an indicator of the eligibility of individual (or group) i for Medicaid, $\delta_{\mathrm{j}}$ and $\tau_{\mathrm{t}}$ are a full set of state and year dummies, respectively.

The key variable in this model, ELIG, is imputed using the simulation models described earlier. For models that are estimated on individual data, the individual's characteristics are used as the basis for the imputation. For models that are estimated on aggregates, average eligibility in that aggregate population is used as the key regressor; for example, for state/year infant mortality, average eligibility in the state/year cell is used. 
These OLS estimates, however, are subject to three sources of bias. The first is omitted variables bias. It is difficult to control for all of the individual determinants of eligibility which might be correlated with utilization or health outcomes; moreover, differences in the financial circumstances of particular places and times (e.g., a recession in a particular state) might be correlated with both eligibility and the outcome variables of interest (utilization or health). The second is endogeneity: a sick child may cause lower parental income (if a parent is forced to leave work to care for the child, for example), leading to a spurious positive correlation between Medicaid eligibility and utilization. Finally, there may be substantial measurement error in the eligibility indicator, given the limitations of standard survey data sets (e.g., the reporting of only annual income instead of the monthly income used by program administrators to assess eligibility).

A solution to all three of these problems is to find an instrument which is correlated with individual eligibility for Medicaid, but not otherwise correlated with the outcome variables of interest. A natural instrument which meets these conditions is one which varies only with the legislative environment in the state and year in which the individual lives. To create such an instrument, which they label "simulated eligibility," Currie and Gruber first select a national random sample of children of each age and of women of child-bearing age in each year. They then assign that same sample to each state in that year and use the eligibility program described earlier to compute average state level eligibility measures for this sample. This measure can be thought of as a convenient parameterization of legislative differences affecting children in different state, year, and age groups-a natural way to summarize the generosity of state Medicaid policy as it affects each group is in terms of the effect it would have on a given, nationally representative population..$^{16}$

This instrumental variables strategy addresses the econometric difficulties noted above. First, by using instruments that are arguably exogenous to utilization or health, they purge the model of endogeneity bias. Second, by using the fraction of the nationally representative population eligible in each woman or child's state/year or state/year/age group, they abstract from any individual-level omitted variables correlated with both eligibility and outcomes. Third, to the extent that the measurement error in the instrument is uncorrelated with the measurement error in the individual eligibility measure, they also surmount the measurement error

16 It is also the national analog to the state-level pre-post analyses described above, which also use only legislative variation. But this provides a means of scaling the differential importance of the law changes across different states. 
problem. Finally, by using a national random sample to construct the instrument, they purge it of the effects of state and year-specific economic conditions that might be correlated with both eligibility and utilization. ${ }^{17}$

\subsection{Combining the States-Utilization Results}

The results of this approach are summarized in Table 6. For pregnant women, Currie and Gruber (1996a) estimate models for the 1979-1992 period; for children, Currie and Gruber (1996b) estimate models for 1984-1992. The first panel shows the effect on utilization of being made eligible for Medicaid, both in absolute (percentage point) terms and in percentage terms (as a fraction of the baseline utilization rate in the sample of eligibles).

The measure of utilization for pregnant women is whether these women delayed their prenatal care until after the first trimester of pregnancy. In fact, in contrast to the pre-post studies described earlier, there is a large improvement in prenatal care utilization associated with Medicaid eligibility. Making someone eligible for Medicaid lowers the odds that they delay prenatal care by almost 50 percentage points, which is essentially a $100 \%$ reduction in the odds of delaying care. Thus, these NLSY data suggest that women made eligible for Medicaid did increase their usage of prenatal care in the direction recommended by the medical literature.

The effect of Medicaid on utilization of children, estimated in Currie and Gruber (1996b), is summarized in the next three rows. Once again, there is a sizeable effect of Medicaid on use of preventive care: being made eligible for Medicaid is associated with a drop of almost $10 \%$ in the probability of going without a visit for over a year; this is almost one-half of the baseline probability of going without a visit. Their other measures of health care utilization for children are less explicitly preventative. There is a smaller rise in the probability of having a visit in the last two weeks, and a significant and sizeable rise in the probability of having a

17 There are two remaining potential problems with this approach. The first is that Medicaid policy itself may be correlated with differences in the outcome variables; for example, rich states may have both more generous Medicaid policy and more medical utilization or better health. Currie and Gruber deal with this problem by including a full set of dummy variables for state, year, and (for children) each single year of age. The second, and related, problem is that these Medicaid expansions may have themselves been endogenous responses by state legislators to perceived problems with medical care access or outcomes. But this "endogenous legislation" scenario is unlikely to be very problematic in this context since much of the permanent variation in eligibility is coming from federal mandates on states of differing initial eligibility generosity, rather than state-specific expansions beyond the federal mandates. As Cutler and Gruber (1996a) note, $90 \%$ of the children and $70 \%$ of the pregnant women made eligible between 1987 and 1992 qualified for Medicaid under federally-imposed minimum guidelines. 
TABLE 6

Utilization and Health Effects of Medicaid Expansions-Summary

Utilization (effects of being made eligible)

Delay prenatal care beyond first trimester

No doctor's visit last year for child

Visit in last two weeks for child

Hospital use last year for child
Absolute effects

$-46.6$

$-9.55$

4.85

3.96
Percentage effects

$-100 \%$

$-49 \%$

$42 \%$

$82 \%$

Health (effects of $10 \%$ eligibility rise)

\begin{tabular}{lll} 
Low birthweight & -0.043 & $-0.63 \%$ \\
Infant mortality & -0.030 & $-2.8 \%$ \\
Child mortality & -0.013 & $-3.4 \%$ \\
\hline
\end{tabular}

Cost per life saved

Infant life

Child life

$\$ 1,026,000$

$\$ 1,610,000$

Notes: First panel shows effects of being made eligible for Medicaid on utilization; percentage effects are as a share of baseline utilization rates in the eligible population. Second panel shows effects of a $10 \%$ eligibility rise, both in percentage point terms and as a share of baseline incidence. Final row in each panel shows implied cost per life saved. From Currie and Gruber (1996a,b).

hospital visit; the estimate implies that being made eligible for Medicaid doubles the odds of a hospital visit in the previous year.

One interesting feature of the expansions is their effect not only on mean utilization but also on the distribution of utilization. Currie and Gruber (1996b) and Currie (1996) explore the differential impact of the expansions by race, education, and immigrant status. In all cases there are some equalization impacts, with the utilization effects being particularly large for blacks, low education groups, and immigrants.

\subsection{Combining the States-Health Outcomes Results}

The remainder of Table 6 investigates effects on health outcomes. The figures in the first column are the absolute (percentage point) effects of a $10 \%$ rise in eligibility. The second column is the percentage effect. For infants, there is a significant and sizeable reduction in infant mortality 
from the overall eligibility changes. For each 10 percentage point rise in eligibility, this estimate implies that infant mortality fell by 0.03 percentage points. The mean infant mortality rate over this period is 1.06 percentage points. Thus, the 30 percentage point rise in eligibility that took place between 1979 and 1992 was associated with a 8.5\% decline in the infant mortality rate. There is a smaller and marginally significant effect on low birthweight.

In Currie and Gruber (1996a), the authors go on to draw a distinction between two types of Medicaid policies during the 1979-1992 period: "targeted" eligibility changes, which were addressed to very low income populations including AFDC recipients; and "broad" changes, which were addressed to somewhat higher income groups. The targeted changes consist of changes in AFDC eligibility, as well as provisions which expanded eligibility to low income women regardless of family structure; these were the source of eligibility changes before 1987 . The broad changes are the income expansions which dominated the second era, 1987-1992. As that paper highlights, these different types of policies affected quite different populations; in particular, the persons covered by broad expansions had higher incomes and were more likely to be privately insured. As a result, one might expect that the policies would have different effects on utilization and health outcomes.

The authors then note that there were in fact quite different effects on outcomes from these two types of policies. There were very sizeable effects of the targeted expansions on mortality, while only insignificant effect of broad expansions: a 30 percentage point increase in targeted eligibility would have been associated with a $11.5 \%$ decline in infant mortality, compared to a $2.9 \%$ decline under the broad policy changes. There is also a very sizeable reduction in the incidence of low birthweight associated with the targeted expansions $(7.8 \%$ for a 30 percentage point eligibility increase), but there is no effect on low birthweight from the broad expansions. ${ }^{18}$ Currie and Gruber (1996a) conjecture that the primary source of difference of these effects was the much lower takeup of the broad expansions than the targeted expansions; they find that takeup was three times higher for the former types of policies.

Medicaid reduces the mortality of older children as well. The authors find that for every 10 percentage point increase in the fraction of children eligible for Medicaid, mortality drops by 0.013 percentage points; the 15.1 percentage point rise in eligibility between 1984 and 1992 is therefore estimated to have decreased child mortality by $5.1 \%$.

${ }_{18}$ Indeed, the increase in prenatal care utilization documented at the top of Table 6 arose during the period of the targeted expansions only. 
A natural means of evaluating these findings is to consider the cost to the Medicaid program per life saved. This is calculated by modeling administrative spending for each state/year on the Medicaid program as a function of changes in eligibility, and comparing these cost changes to any outcome improvements. For infants, the cost is roughly $\$ 1$ million; in fact, when Currie and Gruber once again disaggregate into the targeted and broad policy changes, they find that the cost under the targeted changed $(\$ 840,000)$ was much lower than under the broad expansions ( $\$ 4$ million). For children, the cost per life saved is $\$ 1.6$ million.

These figures for the cost of saving an infant life are quite high, given the common perception in the health community that prenatal care is a cost effective intervention. Indeed, figures given in the Institute of Medicine (IOM) report (1985) suggest that targeting improved prenatal care to high-risk women would cost $\$ 113,000$ per life saved. In fact, the belief that infant lives could be saved at reasonable cost was one of the driving forces behind the adoption of the Medicaid expansions.

There are two possible explanations for this high cost of saving lives. First, the higher figures in Table 6 may reflect the fact that improved prenatal care under the Medicaid program has not been narrowly targeted to high-risk women. If prenatal care designed to reduce preterm delivery was delivered not only to women identified as high risk, but to all pregnant women, the IOM report implies that the cost of saving a life would rise to $\$ 1.06$ million, a figure that is in line with the estimated cost of the targeted expansions.

Another reason for the unexpectedly high costs may be increased use of procedures for childbirth, for a given level of fetal health. Currie and Gruber (1996a) draw an important distinction between individual vs. hospital takeup. While use of prenatal care and other physician services is a function of individual takeup decisions, the use of expensive inpatient hospital services reflects decisions made by both individuals and hospitals. Hospitals have strong incentives to ensure that eligible women who arrive at the hospital to deliver are enrolled in the Medicaid program, since hospitals are required to treat any patient who comes to them for emergency care and are specifically prohibited from turning away women in labor if they participate in Medicaid (U.S. Office of Technology Assessment, 1987). Uncompensated charges to hospitals amounted to $\$ 15$ billion in 1989 (Gruber, 1994a), and childbirth was the single largest component, accounting for $17.4 \%$ of these expenditures (Saywell et al., 1989).

This incentive for hospitals to sign up otherwise uninsured eligibles has always been present, but the incentive became greater with the Medicaid expansions, since they affected so many women. Indeed, the 
U.S. General Accounting Office (1994) reports that in recent years many hospitals have established offices, or contracted with private firms, in order to help Medicaid-eligible patients navigate the often tortuous path towards claiming benefits. Thus, even in the face of limited individual takeup, the expansions may have nonetheless been responsible for a large increase in the number of births financed by the Medicaid program through hospital takeup decisions.

Moreover, once enrolled in Medicaid at the hospital, women may receive much more expensive services than their uninsured counterparts. Evidence from particular procedures with a high level of physician discretion in Hadley et al. (1991) and Wenneker et al. (1990) shows that insured patients receive more intensive hospital treatment than uninsured patients along a number of margins. Thus, hospital takeup could readily result in increased Medicaid costs through shifts in the treatment intensity of newly eligible mothers.

This hypothesis is investigated further in Currie and Gruber (1996c) for the Medicaid expansions over the 1989-92 period. They use information from birth certificate data on utilization of obstetric procedures during childbirth, such as fetal monitoring and cesarean section delivery. They divide the population of women into two groups: teen mothers and high school dropouts ("low education") and all others ("high education"). They note that the extent of takeup and crowdout are likely to be quite different for these two groups, due to the increased familiarity with public assistance and the lower private insurance coverage of the former group. Indeed, when Medicaid and private coverage are modelled as a function of Medicaid eligibility for these two groups, there is $80 \%$ takeup of Medicaid with little crowdout for the low education group, and only $50 \%$ takeup with extensive crowdout for the higher education group. But they also note that even if there is little net increase in insurance coverage for other mothers, this does not mean that there is no effect on their procedure use. Medicaid reimburses hospitals at a much lower level than do most private insurance plans. Thus, crowdout represents a shift from more to less generous insurance coverage for women, which may impact on their procedure use even as their overall insurance coverage status doesn't change.

Currie and Gruber (1996c) employ the same type of methodology described above, but extend the approach to consider separate demographic groups within each state/year cell, allowing them to pursue the low education versus all other split, as described above. In fact, they do find sizeable and significant positive effects of eligibility for Medicaid on the treatment of childbirth for the lower education group; there is a 
uniform increase in the likelihood that women receive each of the procedures documented on birth certificates. ${ }^{19}$ The estimates imply that the $30 \%$ rise in eligibility increased the rate of fetal monitoring or cesarean section delivery by $7.5 \%$.

For the other mothers, however, there is exactly the opposite effect: a significant reduction in the use of three of the four obstetrical procedures studied, and no effect on the other two. Overall, in fact, procedure use was basically unchanged in every case. That is, while Medicaid costs were rising substantially, social costs of treatment were unchanged: women were obtaining the same treatment as before on average, with an equalizing trend towards more intensive treatment for low education groups and less intensive treatment for higher education groups.

\subsection{Supply-Side Policies}

The discussion thus far has focused on policies which increase the demand for medical care. But for a number of reasons it may be supply-side policies which are more effective. As noted above, there is a shortage of physicians willing to serve the Medicaid population. This suggests that increased demand for services generated by expansions of the Medicaid program could go largely unmet, undercutting any potential gains.

One natural supply-side tool is Medicaid fee policy. The low fees paid by state Medicaid programs represent a major potential deterrent to physician willingness to see Medicaid patients. Holahan (1991) reports that the ratio of Medicaid fees to private fees was approximately 0.5 for most procedures surveyed, and 0.56 for total obstetrical care with vaginal delivery. And the Physician Payment Review Commission (1991) found that 38 states identified low fees as the major cause of low physician participation rates. A large body of research suggests that increasing the ratio of Medicaid fees relative to private sector fees will increase physician participation in the Medicaid program (Hadley, 1979; Sloan, Mitchell, and Cromwell, 1978; Held and Holahan, 1985; Mitchell, 1991). Furthermore, Mitchell and Schurman (1984) and Adams (1994) find that the participation of ob/gyns is especially responsive to fee increases.

Of course, higher physician fees are not guaranteed to improve outcomes, due to the physician segregation noted above; only if fee increases generate improvements in access in the places where Medicaid

19 This echoes findings for the state of Massachusetts expansions in Haas et al. (1993b), who showed that this eligibility increase was associated with a rise in the rate of cesarean section delivery. 
recipients live will there be health improvements. Direct evidence on this question is provided by Gruber, Adams, and Newhouse (1996), who examined access to physicians after a large fee increase in Tennessee. They find that there was a sizeable, but insignificant, fall in the average distance of Medicaid patients from a physician.

Currie, Gruber, and Fischer (1995) examine directly the effect of the relative fees paid to physicians by the Medicaid program on infant mortality. They do so by building a state/year physician fee index for the 1979-1992 period. They then model state/year infant mortality as a function of lagged physician relative fees, including once again a full set of state and year dummies. They also model both physician and total spending as a function of the fee ratio. While raising fees will clearly raise physician spending, there may be a countervailing "offset" effect on other spending, if more physician participation shifts Medicaid patients from more expensive hospital outpatient departments and emergency rooms to less expensive physicians' offices. ${ }^{20}$

Their results are summarized in Table 7 . In fact, there is a significant negative, but small, effect of raising physician fees on infant mortality; over the 1979-1992 period, doubling the physician fee ratio would lower infant mortality by $5.2 \%$. An important question, however, is the efficiency of this policy relative to the eligibility expansions. To investigate this question, the authors also regress physician and total expenditures on the fee ratio. Over the entire period, the cost of each life saved in terms of physician expenditures was $\$ 264,000$. At the same time, however, raising physician fees was found to lower hospital spending, perhaps through inducing more efficient care. As a result, fee policy is calculated to be a "free lunch": there is no cost increase but there is a mortality reduction.

The next panel shows that this result is somewhat sensitive to the time period chosen, however. If the sample is restricted to 1983-1992, years for which the authors have higher quality fee data, the estimated impact on infant mortality is larger. At the same time, however, the authors find no offset in hospital costs, so that the cost per life saved is $\$ 1.3$ million. Nevertheless, this is only slightly larger than the cost of eligibility expansions; it is also much lower than the cost of the broad eligibility changes. Thus, physician fee policy may be a cost-effective alternative to eligibility expansions, particularly when eligibility expansions are hitting higher income populations who are being crowded out of private insurance.

20 Gruber, Adams, and Newhouse (1996) investigate this hypothesis directly; they find no offset on the outpatient side, but they do find an offsetting large fall in inpatient spending. 


\section{TABLE 7}

Physician Fees, Infant Outcomes, and Costs

Absolute effects

(per 100 births)

Percentage effects

1979-1992

\begin{tabular}{lll} 
Infant mortality & -0.056 & $-5.2 \%$ \\
Cost per life saved & $\$ 0$ & \\
\hline
\end{tabular}

1983-1992

Infant mortality

Cost per life saved

$-0.074$

$-7.0 \%$

Notes: First panel shows results from 1979-1992 period; second panel shows results from 1983-1992 period. Absolute effects are percentage point effects from a $100 \%$ rise in the physician fee ratio. Percentage effects are these as a share of baseline mortality rate. Final row in each panel shows implied cost per life saved. From Currie, Gruber, and Fischer (1995).

\section{EFFECTS ON THE LABOR MARKET, FAMILY STRUCTURE, AND REDISTRIBUTION}

The discussion thus far has focused purely on the effects of Medicaid on insurance coverage and on health. But, as has been highlighted in the context of other social insurance programs, changes in programs such as Medicaid can have a number of consequences, intended or otherwise, elsewhere in the economy. The purpose of this section is to review the evidence on three other consequences of the Medicaid expansions.

\subsection{Medicaid, Labor Force Participation, and Welfare Participation}

One of the key motivations for health care reform is to reduce perceived inefficiencies in the U.S. labor market arising from the fact that most private insurance is linked to jobs. As a result of this phenomenon, it is suggested that less healthy individuals may be afraid to leave jobs with good private insurance policies, even if better job matches arise, due to fear of losing their health insurance ("job lock"). ${ }^{21}$ A similar phenomenon existed for the AFDC program until the early 1980s. Low income households can obtain fairly high quality insurance through the Medicaid program by being on AFDC. But, if they left the program, they

${ }^{21}$ See Madrian (1994) or Gruber and Madrian (1994) for evidence on the importance of job lock in the U.S. economy. 
entered a low skilled labor market where few jobs offered health insurance. Given the high cost of insurance in the non-group market, this presented a large high cost to those women and children who were otherwise inclined to leave the AFDC program. Following the analogy to the private insurance market, the availability of insurance to low income AFDC recipients provided a form of "welfare lock."

Given the existence of welfare lock, one potential advantage of decoupling Medicaid from the AFDC program is that it could allow individuals to leave AFDC without fear of losing insurance for their children or for the costs of pregnancy. The result would be lower costs of the AFDC program, as well as potential tax revenues from the earnings of these new workers. The magnitude of the welfare lock problem, however, is uncertain: given the harsh job prospects for low income populations, even with health insurance they may be reticent to leave the welfare rolls.

The magnitude of welfare lock has been the subject of a number of studies; see Gruber and Kubik (1995) for a review. Yelowitz (1995a) provides the most convincing estimates of the extent of this phenomenon by studying the effect of the decoupling of Medicaid from AFDC through the Medicaid expansions. This allows him to compare families that are otherwise identical, but who because of differential expansions across states or age groups have different numbers of children covered by health insurance. In this way, he controls for other characteristics of families, and identifies his model solely from legislative variation in Medicaid eligibility.

Using this method on CPS data for 1988-1991, Yelowitz finds statistically significant and large effects of the Medicaid expansions on AFDC participation. His estimates imply that the expansions result in a decrease in AFDC participation of $3.5 \%$, and that increasing the income cutoffs for Medicaid eligibility to children and pregnant mothers by another $25 \%$ of the federal poverty line would decrease AFDC participation by an additional $4.6 \%$. Yelowitz then presents simulation results of extending medicaid coverage to all pregnant women and children with income below $185 \%$ of the poverty line in 1989; the decrease in AFDC caseloads from this policy would save the government approximately $\$ 410$ per female-headed household per year.

\subsection{Medicaid and Family Structure}

A related form of distortion that arises from the traditional structure of Medicaid is an incentive against marriage. That is, in order to qualify for Medicaid, women had to be single mothers on the AFDC program. Given that the potential marriage partners for many welfare mothers 
may not have health insurance to provide for the woman and her children, this could result in the woman remaining single in order to qualify for Medicaid. Yelowitz (1995b) once again uses the structure of the Medicaid expansions of the 1988-1991 period to explore this issue, by assessing whether women who were made eligible for the insurance in the state of marriage were then more likely to get married. He finds a small but significant effect on marriage propensities from the Medicaid expansions through this channel. ${ }^{22}$

\subsection{Medicaid and Redistribution}

A final effect of Medicaid policy to consider is redistribution, as is discussed in Cutler and Gruber (1996b). Even as Medicaid eligibility expansions crowd out the private insurance coverage of those made eligible, it also redistributes income towards that group. As documented in Table 4, the expansion population is largely the working poor-dual parent families with high school degrees but only moderate income. For this group, other public transfers are relatively low; on average, $83 \%$ of income for this group is wage and salary income. Cutler and Gruber (1996b) estimate that families who were crowded out of private insurance received an average income transfer of $\$ 1,523 .{ }^{23}$ Relative to their mean income of $\$ 18,302$, this is an $8 \%$ increase in income, a non-trivial amount for this working-poor population.

\section{SUMMARY AND IMPLICATIONS}

The Medicaid program over the past decade provides a fascinating example of the benefits and limitations of government insurance policy. This example is particularly interesting because there is a wealth of information on the effects of Medicaid policy which can be gleaned from the rich "natural experiment" provided by the Medicaid expansions. To summarize the discussion in the text, there are five main lessons that have been learned about the effects of Medicaid from studying the experience of the expansions:

22 As Yelowitz notes, there is in fact a countervailing influence here. For some women who were married to their husbands just to get health insurance, the increased income cutoffs would allow them to divorce their husbands but maintain coverage. $\mathrm{He}$ is able to distinguish this effect from the marriage incentive effect described above by separating changes in income cutoffs from changes in coverage of traditional families. He finds that both effects are present, but that the positive marriage incentive effect predominates.

23 This calculation assumes that families receive all of the savings from choosing not to purchase employer-provided health insurance (see Gruber (1994b) for evidence on this point), and that for those family members who remain uninsured there are no net financial consequences from dropping insurance. 
1) Dramatic expansions of Medicaid eligibility may only very loosely be translated to increases in Medicaid coverage, due to limited takeup. In fact, only $23 \%$ of children made eligible for the expansions took up coverage.

2) Part of the reason for low takeup is that many individuals who were covered by the expansions already had private health insurance. In fact, many of those who had private insurance dropped that insurance to take up Medicaid: for every two persons who were added to the Medicaid rolls by the expansions, one dropped private coverage.

3) Despite takeup problems, Medicaid was effective in increasing the utilization of preventive care among both pregnant women and children.

4) Medicaid eligibility also was associated with reduced mortality among children and newborns; for the latter group, there were much stronger effects of earlier more limited eligibility changes than of the broader expansions. But these mortality improvements came at a steep cost per life saved. For newborns, it appears that an equally or possibly more cost effective alternative to eligibility expansions is increased provider reimbursement.

5) The Medicaid expansions also had three auxiliary effects outside of the arena of insurance or health changes - they reduced AFDC participation, increased rates of marriage, and effected a redistribution to the working poor.

This broad list of conclusions illustrates the difficulty of drawing simple conclusions about the effect of Medicaid eligibility. Nevertheless, the literature summarized here offers two general lessons/directions for future research.

\subsection{Targeting Matters}

A standard problem faced by all social insurance programs is targeting their benefits to the groups in need. In the case of Medicaid policy, the group in need are those low income persons who are otherwise unable to obtain insurance in the private market. As a result of the unobservability of this characteristic, Medicaid eligibility policy induces both Type I errors (extending benefits to those who don't need them) and Type II errors (not extending benefits to those who do need them). The former is exemplified by the $2 / 3$ of the population covered by the expansions who had private insurance. The latter is exemplified by the $11 \%$ of the population that is uninsured but still not eligible.

But, more importantly, the latter consists also of individuals who are actually eligible, and who are in need of public coverage, but who do not take up their benefits. Takeup here consists either of signing up at all, or 
of signing up appropriately. For example, even though most pregnant women will be made aware of their Medicaid eligibility when they go to the hospital to deliver their babies, the fact that they did not know earlier, and did not use earlier prenatal care, is a lack of takeup. There could be potential efficiency gains to the Medicaid program by shifting dollars from the "crowded out" group to the group that is truly in need but is either not eligible or does not (appropriately) take up.

Policy alternatives for addressing low takeup by needy groups are relatively straightforward, and involve outreach to the population at risk. Indeed, several states have adopted public relations campaigns with themes such as "Baby Your Baby" (Utah) or "Baby Love" (North Carolina) to accompany expansions in Medicaid eligibility. Buescher et al. (1991) find that the North Carolina program had significant positive effects on the utilization of prenatal care and on birth outcomes.

Minimizing crowdout without disqualifying needy applicants, however, is more difficult. There are several options here. The first is to resort to the type of "ordeal" mechanisms described by Nichols and Zeckhauser (1982) as a means of improving targeting. For example, a waiting period could be imposed between when an individual loses private coverage and when they become eligible for Medicaid, or individuals could be excluded from Medicaid coverage entirely if they are offered but decline private coverage. ${ }^{24}$ This type of mechanism would be hard to monitor, however, and it is possible that it could lead to even higher levels of uninsurance, as individuals decide to forgo private coverage for the required waiting period.

An alternative would be to make Medicaid less attractive, without removing its basic insurance properties. As noted above, currently Medicaid enrollees pay none of the costs of their care while those with private insurance pay about one-third on average. Thus, moving towards increased copayments and deductibles for Medicaid enrollees would make it a much less attractive option, while maintaining its essential (catastrophic) insurance features, with basic immunization and preventative care visits covered. In theory, the program could even move to the type of income-related copayment schedule advocated by Feldstein (1971) and analyzed by Feldstein and Gruber (1995), where copayment rates are high but they are limited as a share of income (for example, 10\% of income). This would allow Medicaid to expand even further up the income distribution without as much crowdout, since it would not be

${ }^{24}$ Indeed, this is exactly the structure of a recent subsidy program for the purchase of private insurance in Minnesota: individuals must have been uninsured for 18 months or more, and can not work at a job that offers health insurance. 
particularly attractive to higher income persons. At the same time, supply-side restrictions could be introduced, making Medicaid more of a "managed care" program along the lines of private insurance. ${ }^{25}$ These restrictions will once again make the program less attractive relative to private insurance, while maintaining its essential insurance features.

A more radical alternative here would be to forgo entirely the provision of public insurance, and to simply subsidize the purchase of private insurance, with a sliding scale that offers high subsidies for very low income persons but which declines as income rises. This approach would provide subsidies to everyone in a given income range, but would induce less distortion across types of insurance. However, given the problems with the individual insurance market, this approach is not guaranteed to have important impacts on private insurance coverage. The evidence on the elasticity of response to private insurance subsidies is mixed; see Gruber and Poterba (1996) for a review. Future research in this area could usefully focus on the relative insurance impacts of public insurance provision versus private insurance subsidization.

\subsection{Evaluate Cost-Effectiveness}

The success of public insurance policy cannot be measured solely by its impacts on health; the costs of any health improvements must be considered as well. In fact, the evidence reviewed above illustrates that Medicaid eligibility expansions saved lives only at a very high cost $(\$ 1$ million per infant life or $\$ 1.6$ million per child life). Are these costs per life saved high or low? There are several natural benchmarks to which they can be compared.

The first is relative to the distribution of resources within the Medicaid program, and in particular to supply-side interventions such as higher fees. As noted earlier, fee increases may be at least as cost effective as increases in eligibility in terms of improving health outcomes. And lower reimbursement to hospitals for very expensive interventions may have little impact on outcomes while substantially reducing costs. Perhaps the most important direction for future research on Medicaid is to distinguish the effect that different interventions have on the production of health and on costs, in order to inform policy makers of their relative efficacy.

25 Indeed, many state Medicaid programs have introduced reforms along these lines in recent years. Another alternative for making Medicaid less attractive is to explicitly restrict the package of services that would be covered, as was attempted by the Oregon Medicaid program. This approach runs into many problems in practice, however, as particular exclusions draw attention to perceived horizontal inequities in coverage (see Strosberg et al. (1992) for a further discussion of the implications of the Oregon plan). 
TABLE 8

The Value of a Life

\begin{tabular}{|c|c|c|}
\hline Source & Type of risk & $\begin{array}{c}\text { Value } \\
\text { (millions of \$) }\end{array}$ \\
\hline Manning et al. (1989) & Willingness to pay & 1.66 \\
\hline \multirow{3}{*}{$\begin{array}{l}\text { Viscusi (1993)- } \\
\text { Compensating } \\
\text { differentials }\end{array}$} & Labor market risk of death & $3-7$ \\
\hline & $\begin{array}{l}\text { Other tradeoffs outside of } \\
\text { labor market }\end{array}$ & 4 \\
\hline & Survey evidence & $0.1-16$ \\
\hline \multirow[t]{6}{*}{$\begin{array}{l}\text { Tengs et al. (1995)_-Life } \\
\text { saving interventions }\end{array}$} & $\begin{array}{l}\text { Child restraint system for } \\
\text { cars }\end{array}$ & 5.3 \\
\hline & $\begin{array}{l}\text { Child-resistant cigarette } \\
\text { lighters }\end{array}$ & 3.6 \\
\hline & $\begin{array}{l}\text { Flammability standard for } \\
\text { children's sleepwear, } \\
\text { size } 0-6\end{array}$ & 0 \\
\hline & $\begin{array}{l}\text { Flammability standard for } \\
\text { children's sleepwear, } \\
\text { size } 7-14\end{array}$ & $3.4-12$ \\
\hline & $\begin{array}{l}\text { Flammability standard for } \\
\text { children's clothing, } \\
\text { size } 7-14\end{array}$ & 1126 \\
\hline & School bus safety & $11.2-367$ \\
\hline
\end{tabular}
Note: Table reports estimates of the value of a life from sources cited in first column, according to
methods cited in second column.

A more difficult issue involves comparing the value of dollars devoted to the Medicaid program to dollars spent elsewhere. On the one hand, the figures in Table 6 and 7 are very large relative to other investments society makes in children. For example, the $\$ 1.06$ million per life saved from the targeted expansions to pregnant women would pay for 260 child/years of elementary/secondary education, 312 family/years of AFDC benefits for the typical 2-person family, or 353 child/years of Head Start preschool. ${ }^{26}$

On the other hand, studies of the value of an adult life generally arrive at figures that exceed our estimated cost of saving a life via Medicaid policy. These studies are reviewed in Table 8. Manning et al. (1989) use data from studies of willingness to pay for a small change in the probabil-

${ }^{26}$ Cost of education is average expenditures per student from U.S. Department of Education (1991); AFDC costs are from the AFDC benefits data used in this paper; Head Start costs come from Stewart (1992). 
ity of survival to estimate a value of life of $\$ 1.66$ million. Viscusi (1993) summarizes studies based on compensating differentials for risk of death on the job and concludes that the most reliable estimates range from $\$ 3$ to $\$ 7$ million per life saved. A similar estimate is obtained from his most reliable study using non-labor market data. Survey evidence on the value of a life, however, obtains a very wide bound on value, ranging from 0.1 to 16 million.

However, although the literature on compensating differentials suggests that the value of a life falls with age since fewer years of life are saved for older workers (Moore and Viscusi, 1988), the value of a newborn life may be much less than that of a prime-age adult because investments in human capital have not yet been made. Also, the compensating differentials literature implies that the value of life rises with income because higher income persons are willing to pay more to save their lives (Evans and Viscusi, 1993). The impact of Medicaid policy, and particularly of the targeted policy changes, is concentrated among low income populations. Hence, to value an infant life using estimates derived from studies of compensating wage differentials, one would have to somehow adjust both for differences in human capital and for differences in income levels. Whether the Medicaid policy changes would appear cost-effective after these adjustments were made is unclear.

A second way to use the compensating differentials framework would involve viewing children as a consumption good and examining the tradeoffs parents are willing to make in order to protect children, born and unborn, from potential hazards such as dangerous chemicals. We are unaware of any studies of this issue. ${ }^{27}$

An alternative means of assessing cost effectiveness is to compare the cost of saving a life via Medicaid policy to the costs of saving a life via other government interventions; if the government mandates that at least $\$ 1.6$ million be spent to save newborns and children through other channels, then the expansions could be viewed as relatively cost-effective. Tengs et al. (1995) review several alternative government interventions aimed directly at children, and find that most of them cost substantially more than $\$ 1.6$ million, as Table 8 shows. For example, child restraint systems in cars cost $\$ 73,000$ per life/year saved, or $\$ 5.3$ million for a child with a 74.8-year life expectancy (the average for children born in 1986). Other interventions are much more expensive, some costing upwards of

27 Alternatively, if children are viewed as consumption goods, one could claim that the value of a newborn was the cost of adoption or of hiring a surrogate mother, both of which are much lower than the cost to Medicaid of saving an infant (see Economist, 1988). 
$\$ 1$ billion per life saved. By this metric then, the Medicaid expansions were fairly cost-effective.

There are two further complications to making this comparison. First, the figures for the cost of saving a life do not value health improvements short of mortality reductions. Mortality is a relatively crude measure of health improvements; to the extent that Medicaid coverage improves health status along other margins as well, this raises further the cost effectiveness of the program. Second, as Currie and Gruber (1996c) find, the social cost of the broad expansions to pregnant women may have been much lower than the cost to the Medicaid program, because some of the increased costs to Medicaid represent reduced costs to private insurance. Thus, an appropriate calculation of the net costs involves incorporation of the marginal deadweight loss from raising the funds through the public sector relative to financing the expenses through private insurance. Finally, as Cutler and Gruber (1996b) highlight, there is important implicit redistribution coming through the Medicaid expansions. For example, consider comparing saving a life through Medicaid versus increasing educational expenditures: as noted above, Medicaid redistributes resources to a low income group which has traditionally not received many government transfers, whereas educational spending may largely transfer resources to higher income groups. ${ }^{28}$

In measuring the value of increased Medicaid spending, one aspect to consider which has not played a large role in debates thus far is coverage of other groups in the population. The primacy given to children and pregnant women in health insurance policy-making may be warranted, given the potential long-term benefits of low cost interventions early in life (such as improved prenatal care or immunization). But covering women of child-bearing age at all times, rather than just while pregnant, may prove to be cost-effective policy. One reason for low utilization of prenatal care among those made eligible for pregnancy coverage in recent years is that women find out about their eligibility too late in their pregnancies. This may not be the case if they are continuously covered. Moreover, it may be that maintaining a constant high level of healthiness is more important for the ultimate development of infants than is the particular pattern of prenatal care.

${ }^{28}$ These two issues may even be in conflict in comparing alternative Medicaid interventions. For example, financial incentives to physicians to see Medicaid patients may be a more cost effective means of saving lives than eligibility expansions, but it has less attractive distributional properties. 


\section{REFERENCES}

Adams, Kathleen (1994). "The Effect of Increased Medicaid Fees on Physician Participation and Enrollee Service Utilization in Tennessee." Inquiry 31:173-189.

American Medical Association (1991). Physician Marketplace Update, July 1991. Chicago, IL: AMA.

Bindman, A. et al. (1990). "A Public Hospital Closes: Impact on Patients' Access to Care and Health Status." Journal of the American Medical Association 264:2899-2904.

Blank, Rebecca, and David Card (1991). "Recent Trends in Insured and Uninsured Unemployment: Is There an Explanation?" Quarterly Journal of Economics 106:1157-1190.

Blank, Rebecca, and Patricia Ruggles (1996). "When Do Women Use AFDC \& Food Stamps? The Dynamics of Eligibility vs. Participation." Joumal of Human Resources 31:57-89.

Buescher, Paul A. et al. (1991). "An Evaluation of the Impact of Maternity Care Coordination on Medicaid Birth Outcomes in North Carolina." American Journal of Public Health 81:1625-1629.

Currie, Janet (1996). "Do Children of Immigrants Make Differential Use of Public Health Insurance?" UCLA. Mimeograph.

, and Jonathan Gruber (1996a). "Saving Babies: The Efficacy and Cost of Recent Changes in the Medicaid Eligibility of Pregnant Women." Journal of Political Economy. Forthcoming.

(1996b). "Health Insurance Eligibility, Utilization of Medical Care, and Child Health." Quarterly Journal of Economics 111:431-466.

(1996c). "The Technology of Birth: Insurance Coverage, Medical Interventions, and Infant Health." NBER. Mimeograph.

_, and Michael Fischer (1995). "Physician Payments and Infant Mortality: Evidence from Medicaid Fee Policy." American Economic Review 85:106-111.

Cutler, David, and Jonathan Gruber (1996a). "Does Public Insurance Crowd Out Private Insurance?" Quarterly Journal of Economics 111:391-430.

(1996b). "The Effect of Expanding the Medicaid Program on Public Insurance, Private Insurance, and Redistribution." American Economic Review 86:368-373.

(1996c). "Medicaid and Private Insurance: Evidence and Policy Implications." Health Affairs. Forthcoming.

Dubay, Lisa and Genevieve Kenney (1996). Did the Medicaid Expansions for Pregnant Women Crowd out Private Coverage? Health Affairs. Forthcoming.

Economic Report of the President, 1995. Washington, DC: U.S. Government Printing Office.

Economist, "Morals Meet the Market." 308, no. 7557, July 2, 1988.

Ellwood, Marilyn R., and Genevieve Kenney (1995). "Medicaid and Pregnant Women: Who Is Being Enrolled and When?" Health Care Financing Review, Winter:7-28.

Employee Benefits Research Institute (1995). EBRI Databook of Employee Benefits. Washington, DC: EBRI.

Evans, Willian N., and W. Kip Viscusi (1993). "Income Effects and the Value of Health." Journal of Human Resources 28:497-518. 
Feldstein, Martin (1971). "A New Approach to National Health Insurance." The Public Interest 23:93-105.

_ and Jonathan Gruber (1995). "A Major Risk Approach to Health Insurance Reform." In Tax Policy and the Economy, vol. 9, James M. Poterba (ed.). Cambridge: MIT Press.

Fossett, James W., Janet D. Perloff, Phillip R. Kletke, and John A. Peterson (1992). "Medicaid and Access to Child Health Care in Chicago." Journal of Health Politics, Policy and Law 17:273-298.

_, and John A. Peterson (1989). "Physician Supply and Medicaid Participation: The Causes of Market Failure." Medical Care 27:386-396.

Fuchs, Victor R. (1974). Who Shall Live. New York: Basic Books.

Government Accounting Office (1991). Medicaid Expansions: Coverage Improves but State Fiscal Problems Jeopardize Continued Progress. Washington, DC: GAO.

Gruber, Jonathan, (1994a). "The Effect of Competitive Pressure on Charity: Hospital Responses to Price Shopping in California." Journal of Health Economics 13:183-212.

(1994b). "The Incidence of Mandated Maternity Benefits." American Economic Review 84:622-641.

_, Kathleen Adams, and Joseph Newhouse (1996). "Physician Fee Policy and Medicaid Program Costs." MIT. Mimeograph.

, and Jeffrey D. Kubik (1995). "Health Insurance and Welfare Participation: A Literature Review." MIT. Mimeograph.

, and Brigitte C. Madrian (1994). "Limited Insurance Portability and Job Mobility: The Effect of Public Policy on Job-Lock." Industrial and Labor Relations Review 48:86-102.

- and James M. Poterba (1996). "Fundamental Tax Reform and EmployerProvided Health Insurance." Forthcoming in Brookings Institution volume on Fundamental Tax Reform, Henry Aaron and William Gale, eds.

Hadley, Jack (1979). "Physician Participation in Medicaid: Evidence from California." Health Services Research 14:266-280.

-, Earl Steinberg and Judith Fader (1991). "Comparison of Uninsured and Privately Insured Hospital Patients: Condition on Admission, Resource Use, and Outcome." Journal of the American Medical Association 265:374-379.

Haas, Jennifer S., Seven Udarhelyi, Carl N. Morris, and Arnold M. Epstein (1993a). "The Effect of Providing Health Coverage to Poor Uninsured Pregnant Women in Massachusetts." Journal of the American Medical Association 269:87-91.

, Seven Udarhelyi, and Arnold M. Epstein (1993b). "The Effect of Health Coverage for Uninsured Pregnant Women on Maternal Health and the Use of Cesarean Section." Journal of the American Medical Association 270:61-64.

Held, Philip J., and John Holahan (1985). "Containing Medicaid Costs in an Era of Growing Physician Supply." Health Care Financing Review 7(1):49-60.

Holahan, John (1991). "Medicaid Physician Fees, 1990: The Results of a New Survey." Urban Institute Working Paper no. 6110-01.

Howell, E.M., and Marilyn Ellwood (1991). "Medicaid and Pregnancy: Issues in Expanding Eligibility." Family Planning Perspectives 23:123-128.

Institute of Medicine (1985). Preventing Low Birthweight. Washington, DC: National Academy Press.

Kasper, Judith (1986). "Health Status and Utilization: Differences by Medicaid Coverage and Income." Health Care Financing Review 7:1-17. 
Katz, Lawrence F., and Kevin M. Murphy (1992). "Changes in Relative Wages, 1963-1987: Supply and Demand Factors." Quarterly Journal of Economics 107: 35-78.

Kemper, Kathi (1988). "Medically Inappropriate Hospital Use in a Pediatric Population." The New England Journal of Medicine 243:1033-1037.

Lurie, N., et al. (1984). "Termination from Medi-Cal: Does It Affect Health?" New England Journal of Medicine 111:480-484.

Madrian, Brigitte C. (1994). "Employment-Based Health Insurance and Job Mobility: Is There Evidence of Job-Lock?" Quarterly Journal of Economics 109:27-51.

Manning, Williard G., et al. (1989). "The Taxes of Sin: Do Smokers and Drinkers Pay Their Way?" Journal of the American Medical Association 261:1604-1609.

Mitchell, Janet B., and Rachel Schurman (1984). "Access to Private Obstetrics/ Gynceology Services Under Medicaid." Medical Care 22:1026-1037.

\section{9:645-653.}

Moore, Michael J., and W. Kip Viscusi (1988). "The Quality Adjusted Value of Life." Economic Inquiry 26:369-388.

Mullahy, John (1994). "Medicaid and the Timing of Preventive Health Care for Young Children." Trinity College. Mimeograph.

Newhouse, Joseph (1993). Free for All? Lessons from the RAND Health Insurance Experiment. Santa Monica, CA: RAND Corp.

Nichols, A., and Richard Zeckhauser (1982). "Targeting Transfers Through Restrictions on Recipients." American Economic Review 72:372-377.

Physician Payment Review Commission (1991). Annual Report to Congress, 1991 Washington, DC: The Commission.

Piper, Joyce, Wayne Riley, and Marie Griffin (1990). "Effects of Medicaid Eligibility Expansion on Prenatal Care and Pregnancy Outcome in Tennessee." Journal of the American Medical Association 264:2219-2223.

Rask, Kimberly and Kevin Rask (1995). "Public Health Insurance and Moral Hazard." Colgate University. Mimeograph.

Saywell et. al. (1989). "Hospital and Patient Characteristics of Uncompensated Hospital Care: Policy Implications." Journal of Health Politics, Policy, and Law 14:287-307.

Short, Pamela, and Doris Lefkowitz (1992). "Encouraging Preventive Services for Low-Income Children: The Effect of Expanding Medicaid." Medical Care 30: 766-780.

Sloan, Frank, Janet Mitchell, and Jerry Cromwell (1978). "Physician Participation in State Medicaid Programs." Journal of Humán Resources 8:212-245.

Stewart, Anne (1992). "Head Start: Funding, Eligibility, and Participation." CRS Report for Congress, July 22.

Strosberg, Martin A., Joshua M. Weiner, and Robert Baker with I. Alan Fein (1992). Rationing America's Medical Care: The Oregon Plan and Beyond. Washington, DC: The Brookings Institution.

Tengs, Tammy O. et al. (1995). "Five-Hundred Life-Saving Interventions and Their Cost-Effectiveness." Risk Analysis 15:369-390.

U.S. Congress, Committee on Ways and Means (1994). Green Book 1994: Background Material on Programs Under the Jurisdiction of the Committee on Ways and Means. Washington, DC: Government Printing Office.

U.S. Department of Education (1991). Digest of Education Statistics. Washington, DC: National Center for Education Statistics. 
U.S. General Accounting Office (1994). Health Care Reform: Potential Difficulties in Determining Eligibility for Low Income People. Washington, DC: Government Accounting Office, July.

U.S. Office of Technology Assessment (1987). Neonatal Intensive Care for Low Birthweight Infants: Costs and Effectiveness, OTA-HCS-38. Washington, DC: Government Printing Office.

Valdez, Burciega (1985). The Effects of Cost Sharing on the Health of Children. Publ. no. \$-3270. Santa Monica: RAND.

Viscusi, Kip (1993). "The Value of Risks to Life and Health." Journal of Economic Literature 31:1912-1946.

Wenneker, Mark, Jogi Weissman, and Arnold Epstein (1990). "The Association of Payer with Utilization of Cardiac Procedures in Massachusetts." Journal of the American Medical Association 264:1255-1960.

Yelowitz, Aaron (1995a). "The Medicaid Notch, Labor Supply and Welfare Participation: Evidence from Eligibility Expansions." Quarterly Journal of Economics 105:909-940.

Yelowitz, Aaron (1995b). "Will Extending Medicaid to Two-Parent Families Encourage Marriage?" UCLA. Mimeograph.

Yelowitz, Aaron (1996). "Why Did the SSI Disabled Program Grow So Much? Disentangling the Effect of Medicaid." UCLA. Mimeograph. 